\title{
La comunicación como objeto científico de estudio, campo de análisis y disciplina científica
}

José Luis Piñuel Raigada (Universidad Complutense de Madrid)

Recibido: 20/1 1/09

Aceptado: 11/12/09

RESUMEN: Cada vez son más las investigaciones científicas que han hecho de la comunicación su tema de estudio, pues la revolución tecnológica y el desarrollo industrial en el campo de la comunicación de masas han permitido una creación importante de plataformas y medios que demandan, de forma incesante, la aparición de profesionales encargados de producir contenidos de calidad para la sociedad, llevando a la histórica institucionalización académica de los grados universitarios orientados a la formación superior de los profesionales de la comunicación. Resultado de esta institucionalización es la docencia universitaria de la teoría de la comunicación como materia fundamental, la cual ha sido objeto de una encuesta internacional entre sus profesores y cuyos resultados fueron publicados y debatidos en un simposio celebrado en la Universidad Complutense, en mayo del 2009.

Palabras clave: Epistemología / teoría de la comunicación / modelos teóricos / mediaciones, medios de comunicación.

\section{The communication as a scientific study object, as annalists fill and as scientific discipline}

SUMMARY: The communication studies epistemology's is approach from different alternatives, which rise into the scientific investigation development that studies more and much better the communication, since the technological revolution and industry develop into the mass communication parameter, letting important creation be platforms, and mass media who demands constant appearing of professional in charge to produce a quality purpose for society, leading institutionalize academic college student history in college's degrees, those, made as part of the communication's professional training. The result of this establishment is the teaching of communication's technology as a critical subject. This subject has been the center of an international survey for teachers and students. The results have also been published a debated in a symposium taken part in the Universidad Complutense, may 2009.

Keywords: Epistemilogy / communication theory / theoretical models / mediations / media 


\section{Introducción}

T a institucionalización de los disLursos científicos con respecto a la comunicación social se sostiene por medio de la puesta en escena de rituales que legitiman las representaciones donde se da cuenta de resultados de investigación (como en los congresos y simposios), pero también apelando a otros rituales (como defender una tesis de Doctorado, superar los ejercicios de una prueba de oposiciones, etcétera), que sirven para el reconocimiento de las competencias académicas de los profesores e investigadores.

Esta última forma de institucionalización progresó en los ámbitos español y latinoamericano mediante la creación y reproducción de las facultades universitarias de Ciencias de la Comunicación/Información, las que requirieron naturalmente cooptar sus académicos por medio de tales rituales de paso. Hoy en España son más de cuarenta las facultades encargadas de impartir enseñanza para los títulos profesionales del campo de la Comunicación: Comunicación Audiovisual, Periodismo, Documentación y Publicidad y Relaciones Públicas; a más de 45 mil se eleva el número de estudiantes que siguen anualmente alguno de los cursos de estas especialidades en los distintos centros universitarios, que hace que el país ibérico se encuentre ante una presión creciente de asumir su responsabilidad, ahora en el continente europeo, en la formación universitaria para el ámbito de la
Comunicación, lo cual constituye un referente, sobre todo para las universidades latinoamericanas, con algunas de las cuales se mantienen importantes relaciones de cooperación.

Merece la pena recordar que el número de universidades inscritas en la Federación Latinoamericana de Facultades de Comunicación Social (Felafacs) e integradas en las asociaciones nacionales de facultades representadas en esta organización se acerca a 218 instituciones (exceptuando Brasil, puesto que este país alcanza más universidades que el resto del Continente).

Con el fin de conocer la situación de la enseñanza universitaria de la Teoría de la Comunicación, la Universidad Complutense de Madrid, a través del grupo de investigación Mediación Dialéctica de la Comunicación Social (MDCS), que me honro en dirigir, y con el auspicio de la Asociación Española de Investigadores de la Comunicación (AE-IC), sección temática de $T^{\mathrm{a}}$ de la Comunicación y Metodología de la Investigación, así como de la Felafacs y de la European Communication Research and Education Association (ECREA), promovió una encuesta que culminó el mes de febrero del 2009, con versiones en inglés, francés, alemán, italiano, portugués y español, que fue contestada por representantes de 237 universidades de Europa y América Latina, con la participación de 363 profesores de más de 40 países, a fin de conocer los perfiles 
de la enseñanza de Teoría de la Comunicación/Información en las universidades europeas y latinoamericanas.

La encuesta centró su atención en los siguientes aspectos de la docencia en Teoría de la Comunicación:

- Datos generales.- Además de recoger los datos básicos del docente y de la universidad a la que pertenece, se preguntó por la denominación de la asignatura, el carácter obligatorio u optativo de su docencia, el número de profesores, la formación dominante de los docentes, la ubicación de la asignatura a lo largo del curso lectivo, el número de horas que se le dedica, etcétera.

- Requisitos, competencias, objetivos y contenidos.- En este conjunto de preguntas se indagó por las destrezas previas requeridas y las competencias que los alumnos deben adquirir al final del curso; los intereses temáticos buscados, es decir, si domina el estudio de paradigmas y de modelos teóricos, o bien de sistemas, procesos y productos; finalmente, si domina la crítica epistemológica.

- Objetos de estudio, campos o saberes disciplinares y paradigmas teóricos. En este bloque se preguntó si en la asignatura dominan como objeto de estudio: la comunicación de masas, la comunicación grupal, la comunicación interpersonal, la comunicación organizacional $\mathrm{u}$ otras prácticas sociales de comunicación; si en relación con los campos o saberes disciplinares de referencia, domina la perspectiva histórica, la sociológica, la antropológica y filosófica, la lingüística y semiótica, la psicológica, una perspectiva interdisciplinaria, o no domina especialmente ninguna; por último, se preguntó por la atención prestada en sus programas docentes por los profesores; a modelos o paradigmas teóricos como el conductismo, el funcionalismo, el estructuralismo, la fenomenología, la teoría de sistemas, los modelos críticos, el informacionalismo, el constructivismo, o si, por el contrario, no brindan predominio de ningún modelo anterior.

- Criterios de evaluación. Esta parte centró su interés en preguntar a los profesores sus criterios para medir los resultados obtenidos, por asistir y participar en clase, por los trabajos individuales y por las pruebas oral y escrita.

En la exposición que sigue presentaremos los resultados más relevantes asociados al punto tercero, Objetos de estudio, campos o saberes disciplinares y paradigmas teóricos, de forma que pueda iniciarse un debate sobre el estado actual de la epistemología en torno a los estudios de comunicación.

\section{Antecedentes y estado de la cuestión}

Antes de lanzar la encuesta, en el grupo de investigación nos habíamos planteado esta interrogante: ¿qué ocu- 
rre en el ámbito de la epistemología científica con la Teoría de la Comunicación? Hoy sabemos que en todas las épocas históricas $-\mathrm{y}$ aun en aquellas que denominamos "prehistóricas" los colectivos humanos han desarrollado rutinas, pautas, habilidades, etcétera, por medio de las cuales se crea y reproduce un capital cognitivo que, sostenido por prácticas comunicativas y transmitido de generación en generación, garantiza la confianza o la seguridad sobre las actuaciones que la sociedad prescribe llevar a cabo para su reproducción, y ello hasta el punto de que la reproducción biológica de nuestra especie terminó por supeditarse a la reproducción social de los grupos humanos, sin la cual aquella resulta ya poco viable.

En primer lugar, por las ciencias de la naturaleza hemos llegado a comprender, precisamente, cómo la comunicación permite a los seres vivos ir configurando un dominio de existencia propio, al que se incorporan en forma recíproca y dialéctica las habilidades de la especie y las oportunidades que les brinda el entorno (cfr. Maturana y Varela 1995, 1996).

En segundo lugar, por las ciencias humanas entendemos cómo la comunicación llega a ser un comportamiento específico determinante en la evolución del individuo (en su maduración personal y social, cfr. Vigotsky 1988), pero también en la construcción de identidades, hábitos, escenarios e imaginarios sociales, sin los cuales ni el conocimiento compartido ni las relaciones humanas en sociedad se pueden reproducir (cfr. Luhmann 1991).

En tercer lugar, hemos llegado a comprender, además, cómo la comunicación es el universo respecto al cual adquieren vida y vigencia las reglas del lenguaje, las normas de la lengua y los discursos expresivos; pero que, recíprocamente también, reglas, normas y discursos contribuyen a enriquecer y reproducir el universo de la comunicación (Deacon 1997).

En cuarto lugar, por la Arqueología y las ciencias etnográficas sabemos cómo la escritura y su evolución cultural muestra esa dialéctica entre comunicación y lenguaje, promoviendo la reproducción del conocimiento socialmente vigente, de generación en generación (Garfinkel 1967).

En quinto lugar, con la experiencia de la escritura llega el titubeo sobre la mejor adecuación entre expresiones y representaciones, y que estas dudas aparecen tanto si se considera el desarrollo del individuo, como la evolución de las culturas, y están en el origen de los discursos que socialmente se imponen para garantizar el conocimiento seguro (con sus criterios de "verdad", tanto míticos como científicos (Lledó 1961; Piñuel y Lozano 2006, cap. 6).

En sexto lugar, van cambiando históricamente estos criterios de verdad cuando se aplican al propio "discurso histórico", el cual proporciona las claves para ubicar en el tiempo y el 
espacio el acontecer de la comunidad propia y de las ajenas (Ranke 1954, Bachelard 1973).

Finalmente, en séptimo lugar, la reflexión científica sobre la comunicación como objeto de estudio ha llevado a repensar el orden natural y el orden social desde la propia práctica social de la comunicación (Leydesdorff 2003; Piñuel y Lozano 2006, cap. 8).

Además, es un hecho que, hasta ahora, todos los grandes pensadores han aportado muy ricas experiencias sobre la actividad comunicativa, y muchas ciencias, y estas muy diversas entre sí, han producido saberes muy importantes a propósito de la actividad comunicativa. También, hasta fechas muy recientes, el caudal de experiencias aportado por pensadores y científicos, y el capital cognitivo acumulado sobre la comunicación, por las diversas ciencias, se ha manifestado, unas veces incompleto, otras demasiado parcelado, y frecuentemente mal organizado debido a la disparidad de criterios teóricos y epistemológicos.

Existe el reto epistemológico de enfrentarse, primero, a cierta excesiva acumulación de saberes que atañen a la comunicación como objeto material de estudio; y evidentemente este empeño ha obligado a los profesores de la materia a repasar los saberes que la Biología, la Psicología, la Lingüística, la Filosofía, la Historia y la Sociología aportan al estudio de la comunicación animal, de la comunicación humana y de la comunicación social; a veces también se plantea examinar tales aportaciones, procurando completarlas hasta constituir un campo de estudio: el de la comunicación; no obstante, este empeño obligaría también a plantearse si existe un paradigma disciplinario susceptible de proporcionar un nuevo enfoque capaz de integrar y reorganizar todos los saberes sobre la comunicación. ¿Se habría llegado así a poner las bases de una nueva "disciplina" científica? ¿Y cómo debería llamarse? ¿Teoría de la Comunicación?

En el simposio celebrado en Madrid en mayo del 2009, y donde se presentaron los datos de esta encuesta, se abordó este debate. $Y$ fueron especialmente las intervenciones de Bernard Miège y Paolo Mancini que más beligerancia mostraron al rechazar la conveniencia de considerar una nueva "disciplina" científica, y de referirse, en todo caso, a la Teoría de la Comunicación como un ejercicio didáctico orientado a pensar y reflexionar sobre las experiencias que la práctica social de la comunicación brinda para el análisis de sociólogos, politólogos, semiólogos, etcétera. ${ }^{1}$

1 El texto completo de todas las ponencias aparecerá publicado por la revista Diálogos de la Felafacs, y además podrán consultarse próximamente en la página web del Grupo MDCS (www.ucm.es/info/mdcs). 
En general, se acepta que una teoría científica, aplicada a un objeto de estudio consistentemente delimitado y definido, adquiere valor si puede poner a prueba el conocimiento y la práctica, pero solo en la medida en que el saber que proporciona pueda mejorar el hacer diseñado por su aplicación $\mathrm{y}$, además, en la medida en que, mientras va facilitando el éxito de la praxis, enriquece y revisa los saberes inicialmente formulados. Ahora bien, las nociones de teoría, así como las nociones de objeto de estudio, campo de conocimiento y de prácticas que revisan el saber se usan a veces bajo requisitos de diferente rigor.

El cuadro 1, "Nociones de teoría y ámbitos de conocimiento", ofrece un ejercicio heurístico que permite comparar en la primera columna nociones de teoría, de mayor a menor rigor, y por filas, los ámbitos de conocimiento a los que aplicarlas según se tome en cuenta si se trata de Objetos de conocimiento", de "Campos de conocimiento" o de "Prácticas que revisan el saber", citando ejemplos en las diferentes casillas.

\section{Cómo plantear "el saber" sobre la comunicación}

En la práctica de la investigación científica y en el discurso que posteriormente da cuenta de ella y permite a los demás científicos reproducirla, los procesos de trabajo pueden orientarse alternativamente a dos objetivos diferentes: uno, coleccionar datos que confirmen un saber previamente formulado, o que hagan posible ampliar el repertorio de detalles que describen a un objeto de estudio o que puedan acercarlos a menores distancias de observación; dos, organizar los datos que sirven para describir un objeto de estudio, revisándolo ya sea en su descripción, en su relación con otros objetos de estudio próximos o en su consistencia epistemológica.

El saber acumulado sobre la comunicación como objeto de estudio en el capital cognitivo que brindan las ciencias se puede exponer, explicar y comentar acudiendo al "cajón" de cada una de ellas y revisando su contenido a la búsqueda de aquellos capítulos y apartados relacionados con la actividad comunicativa de los seres vivos (Biología), con la actividad comunicativa del Homo sapiens (Antropología), con la conducta y el comportamiento humanos (Psicología), con el lenguaje y la escritura (Lingüística), o relacionados con los vestigios culturales y los discursos a través de los cuales conocer el devenir de la historia y del pensamiento humanos (Historia y Filosofía), o, en fin, a la búsqueda de aquellos capítulos y apartados de la epistemología moderna que, tanto desde los saberes sobre la Naturaleza como desde los saberes sobre la Cultura, han pretendido revisar y reorganizar las visiones hasta ahora parciales de las diferentes ciencias, proponiendo reunificarlas desde paradigmas formales nuevos, y uno de ellos ha sido el paradigma de la Comunicación. 
Una "enciclopedia" (del griego $\varepsilon v$,

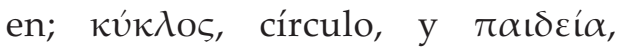
enseñanza) brinda siempre el acceso concéntrico y ordenado - en torno al proceso circular de cada cienciasobre sus saberes. Unas veces este acceso es brindado alfabéticamente, de manera que para cada entrada alfabética del diccionario (entonces llamado "enciclopédico") se ofrecen apartados correspondientes a los saberes que cada ciencia aporta; otras veces es brindado temáticamente, de forma que cada capítulo temático tiene relación con los saberes correspondientes de cada ciencia. Una enciclopedia, por consiguiente, no organiza los saberes desde una única perspectiva del conocimiento sino desde muchas: tantas como entradas tenga un diccionario, o como temas (autores, épocas, descubrimientos, técnicas o, en general, clasificaciones de todo tipo) se propongan para organizar las parcelas (más o menos especializadas o generales) del saber. ${ }^{2}$

\section{Cuadro 1}

Nociones de teoría y ámbitos de conocimiento

Ámbitos de conocimiento

\section{Nociones de teoría}

Objetos de estudio

\section{Campos de conocimiento}

\section{Prácticas que} revisan el saber
Modelo formal de expresiones para representar condiciones de existencia de una referencia.
En ciencias físicas, modelos (generalmente matemáticos) susceptibles de comprobar condiciones empíricas para reproducir experimentalmente un objeto con referencia a $\mathrm{n}$ dimensiones; v.g. Teoría matemática sobre el movimiento del péndulo.
En ciencias de la naturaleza modelos capaces de representar relaciones entre objetos diversos que comparten $n$ dimensiones v.g. ley de la gravitación o ley de la relatividad en Física, leyes de la genética en Biología, etc.
En general, modelos capaces de confrontar representaciones naturales (expresadas por los sujetos estudiados) y representaciones convencionales propuestas por los investigadores, y referidas a comportamientos o prácticas socialmente reguladas sobre objetos que comparten $n$ dimensiones v.g. antropología del conocimiento.

2 Los diccionarios y las enciclopedias temáticas sobre la Comunicación no abundan y, de hecho, como autor tengo larga experiencia biográfica y bibliográfica en la producción de enciclopedias y diccionarios, entre los cuales destaca el Diccionario técnico de comunicación, integrado en la obra de Westfalen, M. H. y Piñuel, J. L. La dirección de comunicación. Práctica profesional y diccionario técnico (1993). 
(continuación)

\section{Ámbitos de conocimiento}

\begin{tabular}{|c|c|c|c|}
\hline Nociones de teoría & $\begin{array}{l}\text { Objetos de } \\
\text { estudio }\end{array}$ & $\begin{array}{c}\text { Campos de } \\
\text { conocimiento }\end{array}$ & $\begin{array}{l}\text { Prácticas que } \\
\text { revisan el saber }\end{array}$ \\
\hline $\begin{array}{l}\text { Representación dis- } \\
\text { cursiva de las condi- } \\
\text { ciones para pensar } \\
\text { una referencia }\end{array}$ & $\begin{array}{l}\text { En general, discursos } \\
\text { científicos que cuestio- } \\
\text { nan los conocimientos } \\
\text { que brindan las disci- } \\
\text { plinas que adquieren } \\
\text { especificidad por su } \\
\text { objeto de estudio, des- } \\
\text { crito por n dimensio- } \\
\text { nes; v.g. gnoseología, } \\
\text { que estudia las formas } \\
\text { de conocer y sus } \\
\text { representaciones, en } \\
\text { las diversas ciencias, } \\
\text { como los fenómenos } \\
\text { naturales en la Física, } \\
\text { las formas vida, en } \\
\text { Biología, o de vida } \\
\text { humana en Antropo- } \\
\text { logía, etc. }\end{array}$ & $\begin{array}{l}\text { En general, discursos } \\
\text { científicos que cuestio- } \\
\text { nan los conocimientos } \\
\text { capaces de ofrecer las } \\
\text { disciplinas que adquieren } \\
\text { especificidad por su } \\
\text { campo de estudio, el cual } \\
\text { comprende diversidad de } \\
\text { objetos que comparten n } \\
\text { dimensiones; v.g. Lin- } \\
\text { güística, cuyo campo } \\
\text { comprende variedad de } \\
\text { lenguas; Psicología, cuyo } \\
\text { campo comprende varie- } \\
\text { dad de comportamientos; } \\
\text { Sociología, cuyo campo } \\
\text { comprende variedad de } \\
\text { sociedades, etc. }\end{array}$ & $\begin{array}{l}\text { En general, discursos } \\
\text { científicos que cuestio- } \\
\text { nan los conocimientos } \\
\text { capaces de brindar las } \\
\text { disciplinas que adquie- } \\
\text { ren especificidad por } \\
\text { centrar su estudio so- } \\
\text { bre comportamientos o } \\
\text { prácticas socialmente } \\
\text { regulados, confrontan- } \\
\text { do las representacio- } \\
\text { nes de los sujetos, las } \\
\text { normas públicas de } \\
\text { actuación y las repre- } \\
\text { sentaciones conven- } \\
\text { cionales propuestas } \\
\text { por los investigadores, } \\
\text { etc.; v.g. Epistemología } \\
\text { de las Ciencias Socia- } \\
\text { les, Epistemología de } \\
\text { la Historia, etc. }\end{array}$ \\
\hline
\end{tabular}

Ordenación intelectual de referencias sobre un objeto, campo o prácticas en estudio
Discursos orientados a discernir y clasificar los saberes compartidos por el intercambio de otros discursos referidos a un mismo objeto de conocimiento; v.g. manuales académicos de disciplinas científicas y enciclopedias y diccionarios temáticos por disciplinas.
Discursos orientados a discernir y clasificar los saberes compartidos por el intercambio de discursos referidos a un mismo campo de conocimiento; v.g. enciclopedias y diccionarios temáticos generales y manuales multidisciplinares de campos científicos.
Discursos orientados a discernir y clasificar los conocimientos que brindan las disciplinas que adquieren especificidad por centrar su estudio sobre comportamientos o prácticas socialmente regulados, ya sea considerando las representaciones de los sujetos, las normas públicas de actuación o las representaciones convencionales propuestas por los investigadores; v.g. crítica social, crítica del conocimiento, crítica cultural, etc. 
Teorizar en Comunicación no es, por consiguiente, hacer una enciclopedia de la comunicación. Pero cuestionar la propuesta de "teoría(s) de la comunicación" tampoco. Puede ayudar, sin embargo, para que en la comunidad científica se llegue a alcanzar el momento de proponer una "teoría de la comunicación" que podrá adquirir la suficiente consistencia epistemológica si se define bien el objeto: qué se entiende por Comunicación, y a partir de ahí proponer un diseño epistemológico y metodológico capaz de formular problemas y vías de solución, tanto para conocer mejor todos los aspectos que sean relevantes respecto de ese objeto de estudio (planteando sus relaciones: temporales, causales, etcétera), así como para aplicar mejor ese conocimiento a las prácticas humanas donde se hace presente la comunicación, facilitando con ello que el conocimiento de la comunicación como objeto, el análisis de los campos donde la comunicación se hace presente, y la práctica de la comunicación, recíprocamente se puedan enriquecer, progresar y reproducirse.

En este sentido, respecto de la comunicación se podría plantear un cuadro que contemple los ámbitos de conocimiento propios de una disciplina capaz de integrar el conocimiento de la comunicación como objeto, el análisis de los campos donde la comunicación se hace presente, y la revisión teórica de los modelos científicos de conocimiento sobre la comunicación, de forma que recíprocamente se puedan enriquecer, progresar y reproducirse.

Cuadro 2

Noción de teoría y ámbitos de conocimiento para la disciplina Teoría de la Comunicación

\begin{tabular}{|c|c|c|c|}
\hline \multirow[b]{3}{*}{ 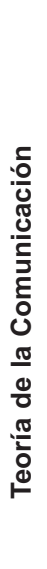 } & \multicolumn{3}{|c|}{ Ámbitos de conocimiento } \\
\hline & $\begin{array}{l}\text { Algunos objetos } \\
\text { de estudio }\end{array}$ & $\begin{array}{l}\text { Campos de } \\
\text { conocimiento }\end{array}$ & $\begin{array}{l}\text { Algunos modelos } \\
\text { que revisan el saber }\end{array}$ \\
\hline & $\begin{array}{l}\text { - Transmisión de señales } \\
\text { - Patrones expresivos } \\
\text { - Comportamiento grupal } \\
\text { - Interacción social } \\
\text { - Lenguaje }\end{array}$ & $\begin{array}{l}\text { - La Física } \\
\text { - La Etología } \\
\text { - La Psicología social } \\
\text { - La Sociología } \\
\text { - La Semiología }\end{array}$ & $\begin{array}{l}\text { - Teoría de la Información } \\
\text { (Shannon) } \\
\text { - Teoría de la Evolución } \\
\text { (Darwin) } \\
\text { - Teoría del Doble Vínculo } \\
\text { (Bateson) } \\
\text { - Teoría de la Espiral del } \\
\text { Silencio (N. Neuman) } \\
\text { - Framing theory (Goffman, } \\
\text { E., Lakoff, G.) }\end{array}$ \\
\hline
\end{tabular}




\section{Cómo sus profesores conciben y enseñan Teoría de la \\ Comunicación}

La encuesta, como ya se ha dicho anteriormente, fue contestada por representantes de 237 universidades de ambos continentes, con la participación de 363 profesores de más de 40 países, a fin de conocer los perfiles de la enseñanza de Teoría de la Comunicación/Información en las universidades europeas y latinoamericanas (cuadro 3).

La invitación para llenar los formularios de la encuesta (mediante comunicación de un enlace electrónico y una contraseña) fue enviada de forma personalizada a todos aquellos nombres integrantes de una lista de cerca de mil profesores de Teoría de la Comunicación extraídos de diversos tipos de fuentes, como páginas web de universidades, bases de datos de miembros de asociaciones científicas de comunicación, (Ecrea, Felafacs, AE-IC, etcétera). Ahora bien, solo una tercera parte contestó la encuesta y no todos hasta el final. Del número de respuestas a los formularios emitidos no puede colegirse representación estadística significativa de un universo que, por otra parte, es finito. De los resultados de la encuesta solo puede colegirse que se trata de un universo completo que, a modo de conjunto de casos clínicos, ofrecen perfiles que desvelan ciertas tendencias en ese universo, pero nada más.

Hecha esta salvedad, los datos que vamos a ir exponiendo y comentando permitirán iniciar un debate, pero no trazar la geografía de percepciones y mentalidades a propósito de los objetos de estudio, campos de conocimiento y modelos teóricos que hayan

Cuadro 3

Países y número de profesores que contestaron la encuesta

\begin{tabular}{lcllllll}
\hline País & Núm. & País & Núm. & País & Núm. & País & Núm. \\
\hline España & 94 & Suiza & 7 & Venezuela & 2 & Irlanda & 1 \\
Brasil & 45 & Turquía & 6 & Argentina & 1 & Luxemburgo & 1 \\
Francia & 31 & Holanda & 5 & China (Macao) & 1 & Marruecos & 1 \\
México & 31 & Chile & 4 & Costa Rica & 1 & Panamá & 1 \\
Reino Unido & 24 & Bélgica & 3 & Dinamarca & 1 & Panamá & 1 \\
Alemania & 16 & Chequia & 3 & Ecuador & 1 & Polonia & 1 \\
Colombia & 14 & Bulgaria & 2 & Eslovenia & 1 & Salvador, El & 1 \\
Italia & 13 & Chipre & 2 & Estados Unidos & 1 & Serbia & 1 \\
Portugal & 10 & México & 2 & Finlandia & 1 & Suecia & 1 \\
Sin identificar & 10 & Perú & 2 & Francia & 1 & Tanzania & 1 \\
Austria & 7 & Rumanía & 2 & (Guayana fr.) & & & Total \\
Cuba & 7 & Uruguay & 2 & & & & 363 \\
& & & & & & & \\
\hline
\end{tabular}


de comprometer la docencia de la Teoría de la Comunicación en Europa y América Latina. Los datos se presentarán a continuación en cuadros donde se ofrecerán resultados de la encuesta agrupados por el idioma en que se practica esa docencia sobre la que se han recabado los datos, resaltando siempre con mayor tamaño los datos referidos a la docencia en español de los países de América Latina, con los cuales podrán compararse los datos referidos a la docencia en español en España, luego los datos de la docencia en portugués (incluyendo las respuestas procedentes de Brasil) y luego los datos de la docencia en francés, inglés, alemán e italiano.

En el gráfico 1 se observan las semejanzas y diferencias que presentan en sus respuestas los profesores de América Latina y de España, así como los profesores francófonos, anglófonos, germanos e ítalohablantes en lo que atañe a la atención con la que privilegian a los diversos objetos de estudio en la docencia de la materia de Teoría de la Comunicación. Según puede advertirse, la comunicación de masas es el objeto de estudio al que se le dedica mayor atención, pues en todos los casos prácticamente ocho de cada diez profesores confiesan que le dedican un interés privilegiado. De los francófonos, por el contrario, solo un 38 por ciento confiesa que le dedican un interés dominante a este objeto de estudio, mientras que los otros dos tercios de profesores francófonos responden que le prestan interés dominante, ya sea a la comunicación de las organizaciones o a otros objetos no comprendidos en la pregunta de la encuesta. A la "comunicación animal" (objeto de estudio comprendido entre las posibles respuestas para elegir) en ningún caso se le dedica atención alguna, y la "comunicación grupal" resalta por recibir la atención ya sea de una exigua minoría o por resultar un objeto de estudio prácticamente no considerado en los programas docentes, como es el caso entre lusófonos y germanohablantes.

En la encuesta también se preguntó si en los principales campos de referencia para el conocimiento domina alguna disciplina o perspectiva, entre ellas las perspectivas histórica, interdisciplinaria, sociológica, antropológica, filosófica, lingüística, semiótica y psicológica, o si por el contrario, no domina ninguna de las anteriores en los programas docentes. Los datos aparecen en el gráfico 2, siguiendo también el orden de los hispanohablantes de América Latina y España, y luego de los francófonos, anglófonos, germanoparlantes e ítalohablantes. Pues bien, hecha la pregunta sobre cuáles son las disciplinas dominantes en los programas de estudio, en el marco geográfico europeo aparecen más frecuentemente la Antropología, la Lingüística, la Semiótica y la Sociología (en este orden), salvo España, donde con más frecuencia aparece la Psicología. La perspectiva histórica y 
transdisciplinar es mayoritaria para América Latina. Pero distinguiendo por grupos de lengua, así como separando el grupo de los hispanohablantes de América Latina y de España, aparecen otros rasgos relevantes. Por ejemplo, mientras más de la mitad de los profesores hispanohablantes de América Latina y de España, lusófonos y germanoparlantes señalan que en sus programas de Teoría de la Comunicación existe un paradigma interdisciplinar dominante; los profesores francófonos y anglófonos no son tan numerosos en señalar la interdisciplinariedad, de forma que aun siendo mayoritarios en adoptar esta perspectiva existen proporciones importantes de profesores francófonos y anglófonos, para quienes la perspectiva disciplinar dominante es la Sociología (concretamente para uno de cada cuatro profesores). Finalmente, apenas existen profesores, sea cual fuere el idioma en el que contestaron la encuesta, que manifiesten que en sus programas domina el campo de conocimientos disciplinar de la Antropología y la Filosofía. Tampoco llegan a dos, de cada diez profesores, sea cual sea el idioma en el que contestaron la encuesta, que manifiesten que su paradigma disciplinar dominante sea la lingüística o la semiótica. Así, pues, en conjunto, en la expresión de un paradigma disciplinar dominante en los programas de Teoría de la Comunicación, estos rasgos apuntan la tendencia progresiva de abandonar los vasallajes disciplinares para la docencia de la Teoría de la Comunicación, especialmente si se trata de aquellas disciplinas con mayor peso especulativo, como la antropología, la filosofía, la lingüística y la semiótica.

\section{Gráfico 1}

Objetos de estudio que dominan en la docencia de Teoría de la Comunicación

\section{Objetos de estudio dominantes en la docencia en español en América Latina}

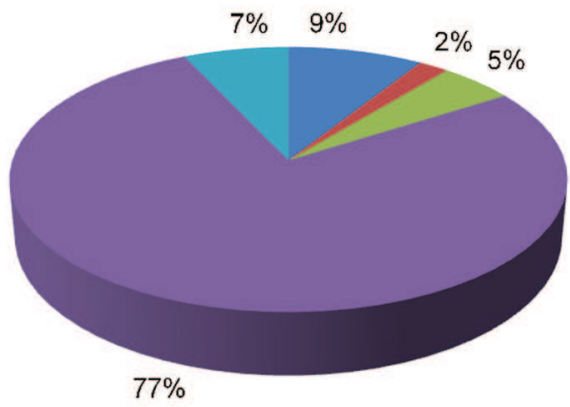

$$
\begin{aligned}
& \text { =Domina comunicación interpersonal } \\
& \text { =Domina comunicación grupal } \\
& \text { = Domina comunicación organizacional } \\
& \text { - Domina comunicación de masas } \\
& \text { = Domina otras aplicaciones }
\end{aligned}
$$


(continuación)

Objetos de estudio dominantes en la materia en España

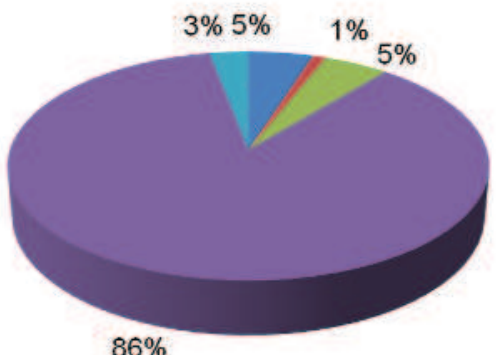

$86 \%$
= Domina comunicación interpersonal

=Domina comunicación grupal

= Domina comunicación organizacional

=Domina comunicación de masas

= Domina otras aplicaciones

Objetos de estudo dominantes na disciplina

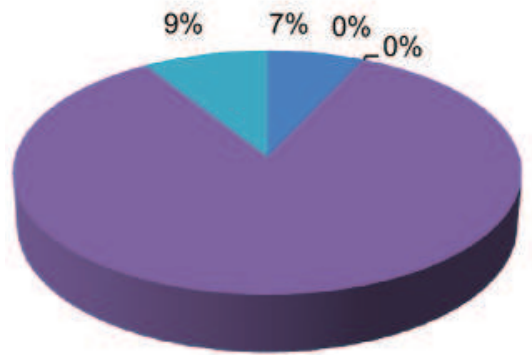

$84 \%$
= Domina comunicaçao interpessoal

= Domina comunicaçao grupal

= Domina comunicaçao organizacional

= Domina comunicaçao de massas

= Domina outras aplicaçöes

Sujets d'étude dominants das les programmes d'études

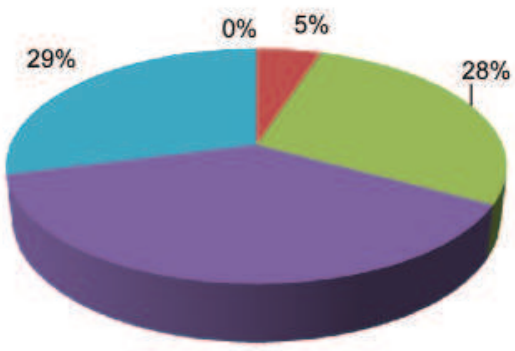

$38 \%$
= La communication interpersonnelle est le sujet dominant

= La communication des groupes est le sujet dominant

= La Communication organisationnelle est le sujet dominant

= La communication de masses est le sujet dominant

= II s'agit d'autres sujets dominant 
(continuación)

Dominating objects of study in the subject

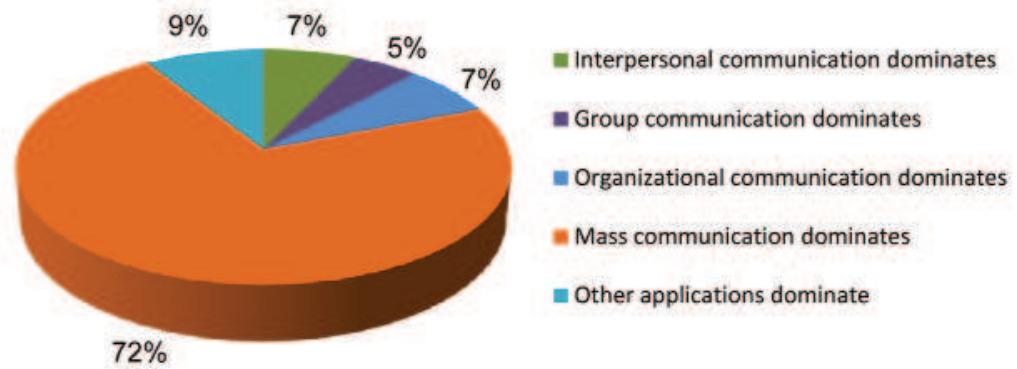

Vorherrschende Studieninhalte des Studienfachs

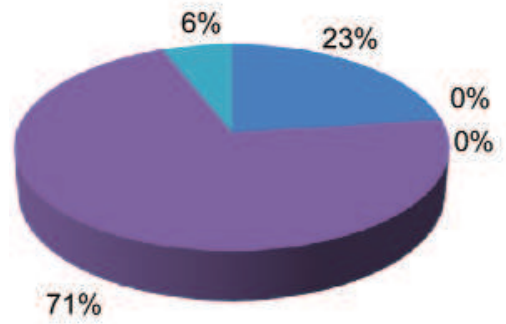

= Hauptsächlich Interpersonell kommunikation

= Hauptsächlich Gruppenkommunikation

= Hauptsächlich organisationskommunikation

- Hauptsächlich Massenkommunikation

= Hauptsächlich andere Anwendungen

\section{Oggetti di studio principali della Materia}

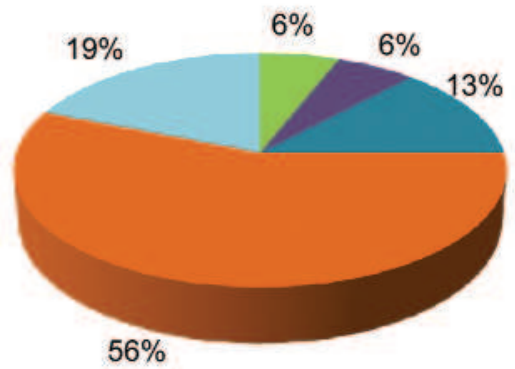
n Prevale Comunicazione Interpersonale
- Prevale Comunicazione Gruppale
a Prevale Comunicazione Organizzativa
Prevale Comunicazione di Massa
Erevalgono altre applicazioni 


\section{Gráfico 2}

\section{Campos de conocimiento que dominan en la docencia de Teoría de la Comunicación}

\section{Paradigmas disciplinarios dominantes}

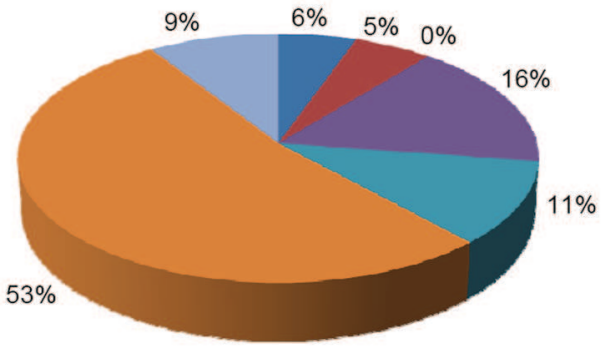

- Dominan Psicología y Psicología Social

- Dominan Lingüística y Semiótica

- Dominan Antropología y Filosofía

Domina la Sociología

nomina la perspectiva histórica

nomina la perspectiva interdisciplinar

No domina ninguna de las anteriores

\section{Paradigmas disciplinarios dominantes}

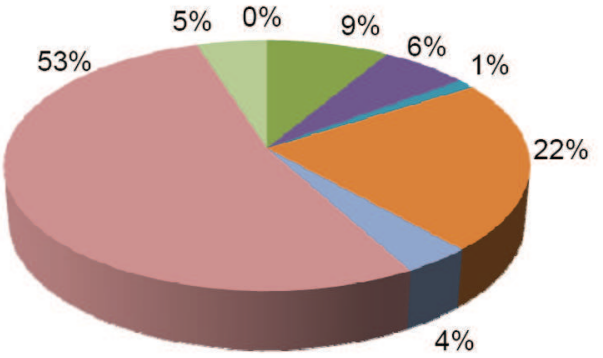

Dominan Psicología y Psicología Social

Dominan Lingüistica y Semiótica

Dominan Antropología y Filosofía

Domina la Sociología

nomina la perspectiva histórica

- Domina la perspectiva interdisciplinar

No domina ninguna de las anteriores

\section{Paradigmas disciplinares dominantes}

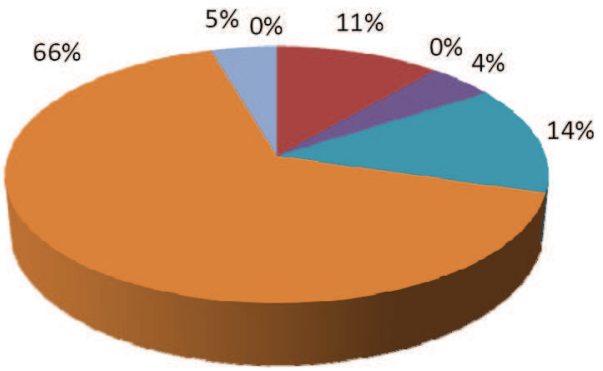

nominam Psicologia e Psicologia Social

n Dominam Lingüística e Semiótica

Dominam Antropologia e Filosofia

Domina a Sociologia

Domina a perspectiva histórica

Domina a perspectiva interdisciplinar

não domina nenhuma das anteriores 


\section{Paradigmes disciplinaires dominants}

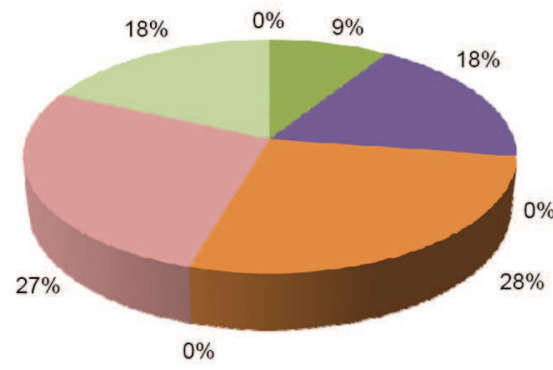

- Le paradigme de la Psychologie et la Psychologie Sociale - Le paradigme de la Linguistique et de la Sémiotique - Le paradigme de l'Anthropologie et de la Philosophie E Le paradigme de la Sociologie - Le paradigme de la vision historique we paradigme de l'approche interdisciplinaire

Aucune des perspectives précédentes n'est la dominante

\section{Dominating disciplinary paradigms}

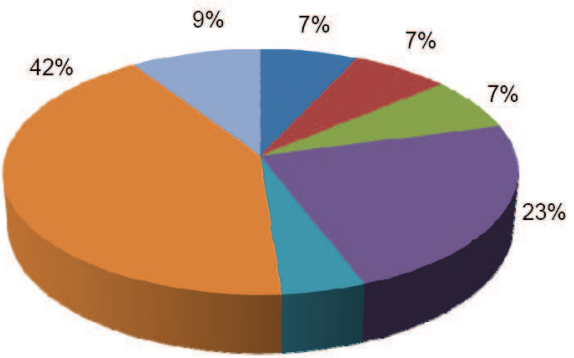

$5 \%$
- Psychology and Social Psychology dominate

- Linguistics and Semiotics dominate

anthropology and Philosophy dominate

- Sociology dominates

- Historical perspective dominates

- Interdisciplinary perspective dominates

ano No of the above dominates

\section{Vorherrschende Paradigmen des Faches}

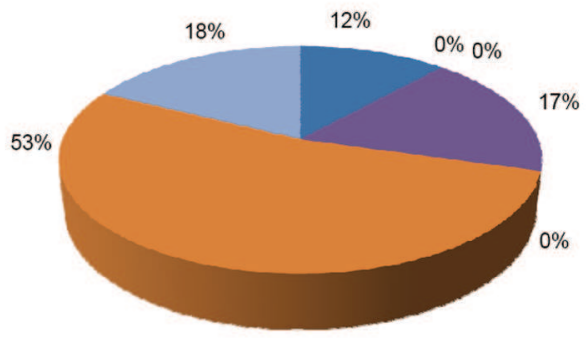

— Hauptsächlich Psychologie und Sozialpsychologie - Hauptsächlich Linguistik und Semiotik

- Hauptsächlich Anthropologie und Philosophie

- Hauptsächlich Soziologie

- Hauptsächlich die historische Perspektive

= Hauptsächlich die interdisziplinäre Perspektive

= Es herrscht keiner der erwähnten Ansätze vor 


\section{Paradigmi disciplinari dominanti}
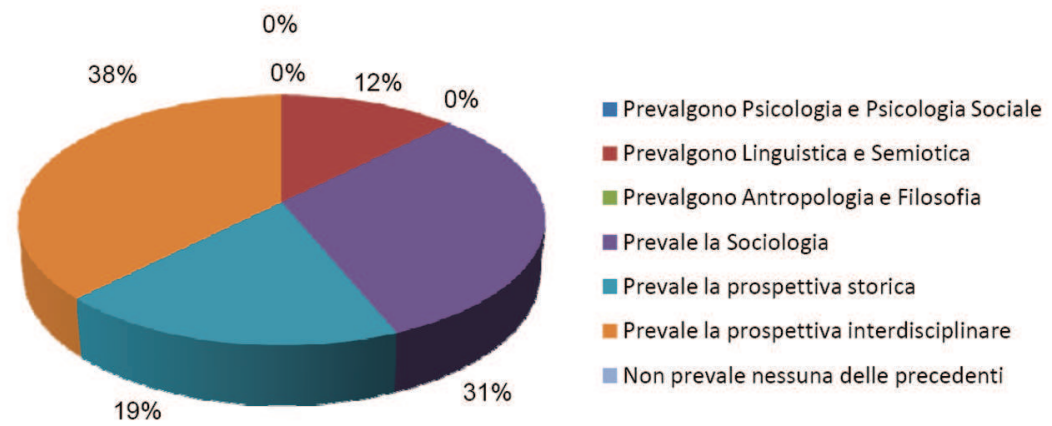

Finalmente, al observar el gráfico 3 se puede comparar cómo los profesores que contestan la encuesta recurren a modelos epistemológicos en la docencia de Teoría de la Comunicación, veremos que solo los profesores hispanohablantes de España y los lusoparlantes se manifiestan en su mayoría (al menos en un 50 por ciento) sin predominio concreto de modelos teóricos como referencia epistemológica en la docencia de Teoría de la Comunicación; la opción de no privilegiar paradigmas epistemológicos es igualmente mayoritaria en todos los idiomas que respondieron a nuestra encuesta. Y si la opción es manifestar un modelo epistemológico dominante se trata de los modelos críticos (Escuela de Frankfurt) para uno

de cada cuatro profesores, tanto si estos son hispanohablantes de América Latina, como lusohablantes o angloparlantes; y para uno de cada cinco entre los profesores ítalohablantes. La siguiente opción de referencia epistemológica relevante es el dominio de los modelos sistémicos, manifestada en segundo lugar por uno de cada cinco profesores francófonos y por uno de cada cinco profesores hablantes de la lengua alemana.

Ahora bien, si los profesores se diferencian no por la lengua en que contestan la encuesta sino por los marcos geográficos de "España", "Resto de Europa" y "América Latina", y se plantea la cuestión de los paradigmas teóricos que epistemológicamente dominan en los programas 
docentes, aparecen curiosos perfiles; los tres marcos geográficos comparten frecuencias similares si de lo que se trata es de considerar dominantes los "modelos funcionalistas" y los "modelos sistémicos", mientras que el "behaviorismo" o el "constructivismo" aparecen como los modelos dominantes en el marco denominado "Resto de Europa". Por su parte, en América Latina se resaltan los "modelos críticos" y el "informacionalismo"; finalmente, en España aparecen dominantes el "estructuralismo" y la "fenomenología" (véase gráfico 4).
A la vista de estos datos, no es de extrañar la existencia de una cierta preocupación por considerar la conveniencia epistemológica de plantear si se justifica o no el encarar los estudios de comunicación como una nueva disciplina, o si se debe formular un paradigma epistemológico capaz de integrar y estructurar los objetos de estudio del universo de la comunicación, los campos disciplinares donde la comunicación se hace presente, y los modelos epistemológicos capaces de explicarla, de forma que recíprocamente se puedan enriquecer, progresar y reproducirse como una ciencia.

Gráfico 3

Modelos teóricos que dominan epistemológicamente la docencia de Teoría de la Comunicación

\section{Modelos teóricos dominantes en América Latina}

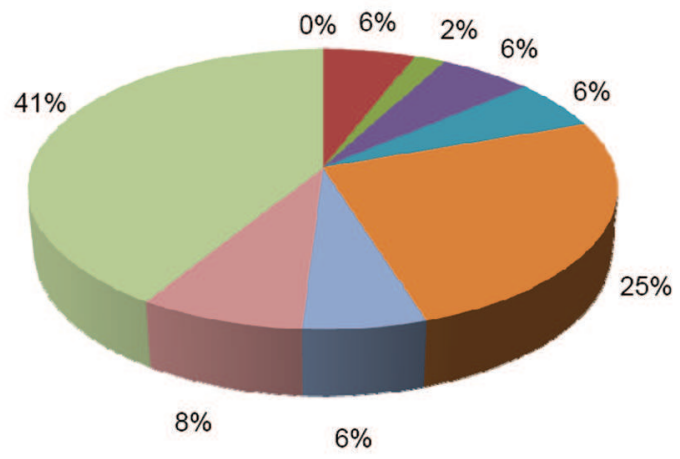

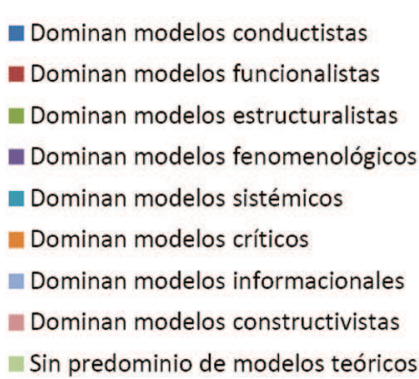

- $\sin$ predominio de modelos teóricos 
(continuación)

\section{Modelos teóricos dominantes en España}

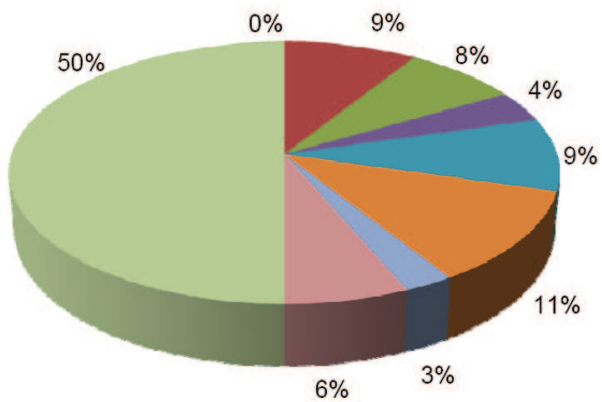

Dominan modelos conductistas

- Dominan modelos funcionalistas

- Dominan modelos estructuralistas

- Dominan modelos fenomenológicos

Dominan modelos sistémicos

= Dominan modelos críticos

an Dominan modelos informacionales

mominan modelos constructivistas

- Sin predominio de modelos teóricos

\section{Modelos teóricos dominantes en lengua portuguesa}

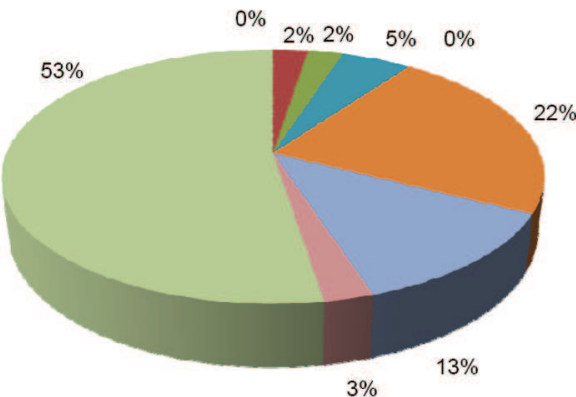
Dominam os modelos condutivistas
nominam os modelos funcionalistas
Dominam os modelos estruturalistas
- Dominam os modelos fenomenológicos
- Dominam os modelos sistêmicos
= Dominam os modelos críticos
Dominam os modelos informacionais
mominam os modelos construtivistas
Não há predomínio de modelos teóricos

\section{Modèles théoriques dominants}

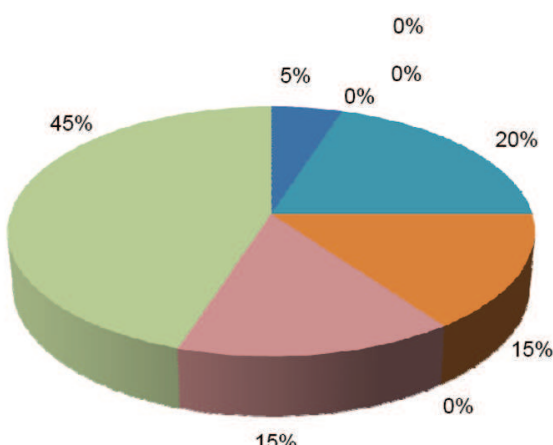

$15 \%$

\author{
Des modèles Behavioristes dominent \\ Des modèles Fonctionnalistes dominent \\ - Des modèles Structuralistes dominent \\ Des modèles Phénoménologiques dominent \\ nes modèles Systémiques dominent \\ Des modèles Critiques sont dominants \\ Des modèles Informationnelles dominent \\ Des modèles Constructivistes dominent \\ a Sans prédominance de modèles théoriques
}


(continuación)

\title{
Dominating theoretical models
}

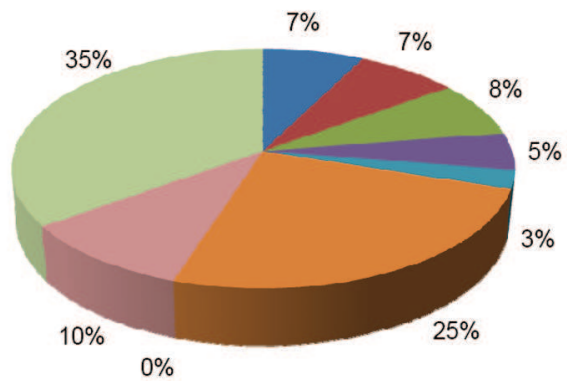

\author{
Behaviourist models dominate \\ - Functionalist models dominate \\ nStructuralist models dominate \\ - Phenomenological models dominate \\ - Systemic models dominate \\ n Critical models dominate \\ - Informational models dominate \\ = Constructivist models dominate \\ No theoretical models predominating
}

\section{Vorherrschende theoretische Modelle}

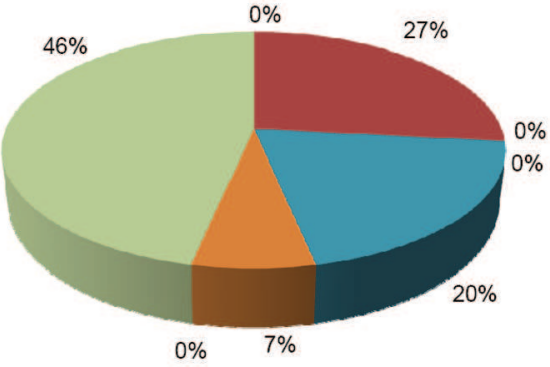

$0 \%$
Es herrschen behavioristische Modelle vor - Es herrschen funktionalistische Modelle vor Es herrschen strukturalistische Modelle vor - Es herrschen phänomenologische Modelle vor Es herrschen systemische Modelle vor Es herrschen kritische Modelle vor as herrschen informationalistische Modelle vor Es Es herrschen konstruktivistische Modelle vor as Es herrschen keine theoretischen Modelle vor

Modelli teorici predominanti

$0 \%$

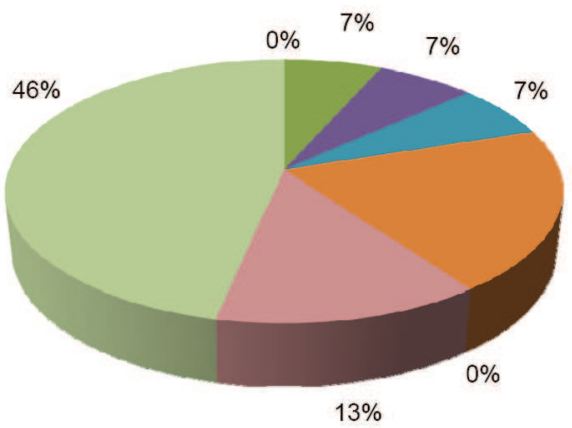

- Prevalgono modelli conduttivisti - Prevalgono modelli funzionalisti - Prevalgono modelli strutturalisti - Prevalgono modelli fenomenologici - Prevalgono modelli sistemici - Prevalgono modelli critici - Prevalgono modelli informazionali - Prevalgono modelli costruttivisti - Senza predominio di modelli teorici 


\section{Gráfico 4}

Modelos teóricos que dominan epistemológicamente la docencia de Teoría de la Comunicación, según marcos geográficos
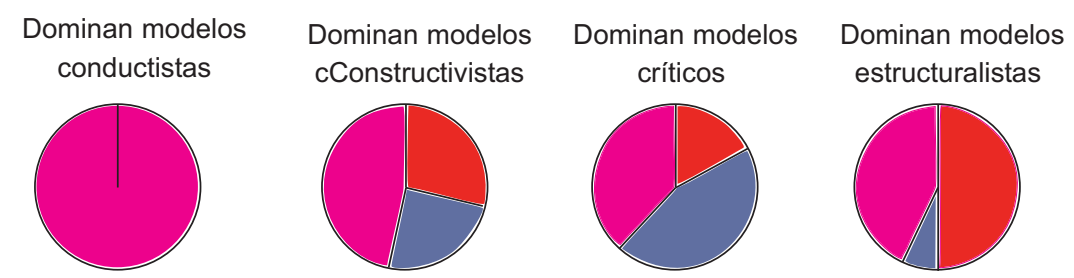

Dominan modelos fenomenológicos
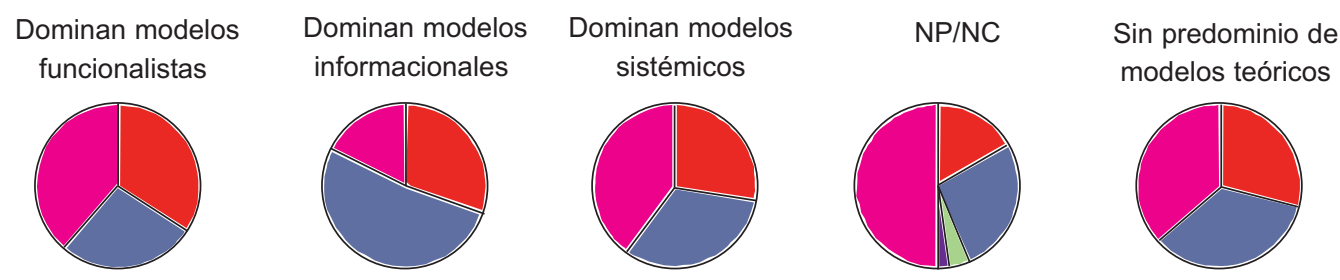

Ámbito geográfico

España $\square$ Latinoamérica $\square$ NP/NC $\square$ Otro $\square$ Resto Europa

\section{Requerimientos para desarrollar una nueva Teoría de la Comunicación}

Un nuevo paradigma epistemológico acorde con estos objetivos debe hacer una distinción neta de las dimensiones que le son propias a la interacción comunicativa como objeto de estudio, frente a las dimensiones que le son propias a la interacción humana considerando el campo de las relaciones sociales, y frente a las dimensiones propias de las prácticas que organizan el comportamiento humano considerando sus representaciones cogniti- vas. Dicho en otros términos, esta nueva Teoría de la Comunicación posible debe afrontar la respuesta más cabal a los problemas siguientes:

- ¿La actividad cognitiva puede desarrollarse sin recurrir a la comunicación?

- ¿Puede, inversamente, desarrollarse la actividad comunicativa sin recursos cognitivos?

- ¿Pueden darse relaciones sociales prescindiendo de interacciones comunicativas?

- ¿Puede, inversamente, haber interacciones comunicativas que no se 
encuentren comprometidas por relaciones sociales?

- ¿Puede haber un capital cognitivo socialmente compartido sin relaciones sociales?

- ¿Pueden haber relaciones sociales sin un capital cognitivo compartido?

Asimismo, debe responder a estas interrogantes:

- ¿La interacción comunicativa puede reproducirse sin capital cognitivo compartido y comprometido por relaciones sociales?

- ¿Puede reproducirse el capital cognitivo compartido y comprometido por relaciones sociales, sin interacción comunicativa?

- ¿Pueden reproducirse relaciones sociales sin capital cognitivo compartido y sin interacción comunicativa?

La formulación de las preguntas precedentes responde a la consideración de que Conocimiento, Sociedad y Comunicación son objetos de estudio formal y materialmente distintos, pero que no pueden desenvolverse, $\mathrm{ni}$ formal ni materialmente, por separado, sino en el interior de un campo compartido, y que la actividad cognitiva, las relaciones sociales y las interacciones comunicativas se condicionan entre sí mediante la indeclinable revisión de sus prácticas.

Esta propuesta teórica deberá asumir que el condicionamiento entre conocimiento, sociedad y comunicación es recíproco, pero también que es secuencial; es decir, si en un momento dado un estado del conocimiento compartido influye sobre el curso que tomen después las relaciones sociales y las interacciones comunicativas, aquel estado del conocimiento compartido también se habrá producido por la concurrencia secuencialmente previa de determinadas relaciones sociales y de determinadas interacciones comunicativas. Por ejemplo, una vez que la existencia de la reproducción in vitro llegó a formar parte del capital cognitivo compartido, las relaciones familiares de las parejas adquieren nuevas alternativas de supervivencia, pero también los hábitos de consumo mediático diferencian a las parejas que son capaces de plantearse esas alternativas principalmente conocidas por la comunicación social; y a la inversa, no se habría llegado al desarrollo científico de la reproducción in vitro sin el cambio previo de las relaciones sociales vinculadas a la convivencia familiar (matrimonio por amor, familias monoparentales, divorcio, etcétera) y sin que la comunicación entre los científicos les hubiera permitido progresar en los ensayos al respecto. Igualmente, una configuración determinada de interacciones comunicativas (por ejemplo las redes sociales de internet) influye sobre el curso que toma después el capital cognitivo compartido (como las destrezas 
informáticas) y sobre las relaciones sociales (como el teletrabajo, el consumo y el ocio); internet ha sido posible también por los avances previos en el capital cognitivo referido a la cibernética y por su rendimiento militar y económico en los procesos de producción. Por último, una configuración determinada de interacciones sociales (como la legalización de las parejas de hecho) influye sobre el curso del capital cognitivo referido a la sexualidad y sobre la frecuencia con que se acude a rituales sociales de boda; asimismo, la legalización de las parejas de hecho fue posible por la presión de la libertad sexual y de los debates mediáticos generadores de corrientes de opinión.

La noción de mediación histórica es la que permite estudiar estos condicionamientos recíprocos y secuenciales; y esta noción implica considerar el capital cognitivo compartido en cada época como mediador de las relaciones sociales y comunicativas, $\mathrm{y}$ mediado por estas; implica también considerar las relaciones sociales, en cada época, como mediadoras del capital cognitivo y de las interacciones comunicativas, así como también considerar las relaciones sociales mediadas, a su vez, por el capital cognitivo y por las interacciones comunicativas; finalmente, la noción de mediación histórica implica entender las interacciones comunicativas, en cada época, como mediadoras del capital cognitivo compartido y de las relaciones sociales $\mathrm{y}$, a su vez, consi- derar dichas interacciones comunicativas mediadas por el capital cognitivo compartido y por las relaciones sociales.

En rigor, este proyecto teórico obliga a acotar, por una parte, las constantes que hayan de ser consideradas en aquello que respecta a cada uno de los objetos materiales de estudio: el capital cognitivo compartido, las relaciones sociales y las interacciones comunicativas; por otra parte, este proyecto teórico también obliga a acotar secuencialmente los estados sucesivos de un campo que comprende el cambio de los momentos históricos del conocimiento, de la sociedad y de la comunicación.

Acotar las constantes que hayan de interesar en el estudio del conocimiento, la sociedad y la comunicación requiere discernir acerca de los elementos sin los cuales es imposible la existencia de un estado de conocimiento, organización social e interacciones comunicativas. De igual modo, acotar secuencialmente los estados sucesivos requiere también discernir teóricamente sobre los criterios en virtud de los cuales se tenga que poner límites al campo espacio-temporal de aquellos estados; no es lo mismo referirse, por ejemplo, al cambio del conocimiento, de las relaciones sociales o de la comunicación a la escala espacio-temporal del devenir biográfico de una pareja familiar que al cambio del conocimiento, de las relaciones sociales o de la comunicación a la escala espacio-tem- 
poral del devenir histórico de una formación social dada, ya sea a pequeña escala (por ejemplo, una comunidad, una empresa o un colectivo religioso) $\mathrm{o}$ a gran escala (una época histórica o una cultura).

Una técnica heurística para representar las constantes referidas a los elementos que integran los procesos y estados de la reproducción del conocimiento, de la reproducción de las relaciones sociales y de la reproducción comunicativa es la representación de estos objetos de estudio mediante esquemas capaces de sistematizarlos en sus componentes y relaciones efectivas y temporales. De igual manera, una técnica heurística para representar los límites espacio-temporales de ese campo de procesos y estados, cuyo cambio se aspira a conocer, consiste en establecer estos límites mediante contornos convencionales que contengan simultáneamente los componentes y las relaciones referidos a una misma escala, para cada sistema de conocimiento, organización social y comunicación considerados. Esto obliga a delimitar siempre un entorno determinado o campo dentro del cual unos mismos individuos, unos mismos recursos materiales, unos mismos productos y unas mismas reglas de orden sean considerados a la vez desde las correspondientes perspectivas cognitivas, sociales y comunicativas, proponiéndose después el examen de las respectivas mediaciones entre ellas. Por ejemplo, a pequeña escala podemos imaginar una situación en que un padre regaña a su hijo; pues bien, esta situación remite directamente a considerar que se trata de una interacción comunicativa, ya que difícilmente se puede "regañar" sin servirse de expresiones verbales y no verbales susceptibles de ser comprendidas por el niño; sin embargo, sería imposible que esta comunicación produjese algún efecto cognitivo (como asociar la "regañina" con el recuerdo de una actuación inadecuada del niño) ni efecto social (por ejemplo el compromiso de obediencia o de respeto en el hijo), si previamente ambos interlocutores (emisor y receptor) no se identificasen respectivamente por los papeles sociales que a cada uno lo comprometen dentro del grupo familiar ("padre" e "hijo") y gracias a un capital cognitivo compartido que les permite reconocerse socialmente, pero también reconocer el significado de los mensajes y su vinculación con recuerdos personales y expectativas de futuro.

\section{Distinguir lo que es comunicación de lo que no es comunicación para saber en qué "tableros" se juega}

Todos los modelos de la comunicación consideran la transmisión de mensajes como su rasgo específico, de forma que sobre este objeto material de estudio cada teoría o cada perspectiva formal ha elegido su punto de 
vista; por ejemplo, para Shannon y Weaver, la fidelidad o la reproducción fiel en el destino de los mensajes emitidos en el origen; o una forma de conducta en los seres vivos y de comportamientos sociales, para otras muchas de las alternativas habidas para explicar la comunicación. A partir de este rasgo específico, por consiguiente, aparecen los diversos enfoques que hacen de la transmisión de mensajes un problema que deben resolver la Física, para diseñar la fidelidad de las transmisiones; la Biología y la Psicología, para explicar las conductas interactivas de los seres vivos; la Lingüística, para dar respuestas al uso de significados y discursos; la Filosofía, para asignar criterios de verdad a las expresiones; la Historiografía, para proporcionar criterios de interpretación a los relatos del acontecer; o la Sociología, para atribuirle a los mensajes que circulan entre los grupos humanos consecuencias propias de la acción social.

Pues bien, la transmisión de mensajes es el rasgo ineludible de la comunicación. A partir de esta constatación, los diferentes enfoques han considerado la transmisión de mensajes teniendo que especificar qué se entiende por mensaje y por transmisión, y cuáles son los criterios para evaluarla. Por ejemplo, si por mensaje se entiende un flujo de señales (modulaciones energéticas) que se transmiten entre dos puntos diferentes del universo físico, el problema es superar las distorsiones sufridas durante la transmisión y la respuesta tiene que ver con el cálculo de su fidelidad; pero si por mensaje se entiende un estímulo de teleacción (o de interacción a distancia) el problema se vincula con las nociones disponibles para distinguir qué son estímulos de conducta, a qué reacciones se vinculan estos estímulos y qué diferencias habría entre estímulos comunicativos y no comunicativos, así como entre reacciones comunicativas y no comunicativas, etcétera; y si por mensaje se entiende expresión, texto, discurso, relato, escenificación, etcétera, entonces los problemas que se plantean desbordan los tableros específicos de la simple transmisión de mensajes y se sitúan en aquellos otros "tableros", donde lo que se juega es el análisis del lenguaje, del pensamiento, de la acción social o de la cultura.

Hemos recordado que las ciencias ya han hecho saber que la transmisión de mensajes se presenta en la conducta de muchos seres vivos y que es un recurso imprescindible en la reproducción social de los grupos humanos y de las sociedades históricas; no se puede prescindir, por consiguiente, de considerar todas aquellas dimensiones ligadas al uso de los mensajes y su transmisión entre los seres vivos y en el seno de los grupos humanos.

Ahora bien, muchas de estas dimensiones preceden la transmisión de mensajes, otras la acompañan y otras la siguen, pero no forman parte 
del juego específico en el que se compromete la propia transmisión. Para distinguir cómo es posible la comunicación y qué es debido al juego de la comunicación, será necesario discernir entre las piezas indispensables en el tablero de la comunicación y aquellas otras que forman parte de otros tableros, donde lo que se juega no es la comunicación sino el comportamiento o la interacción social, pero que cambian o se reproducen según sea el juego de la comunicación que se practique. Y en el tablero de la comunicación, siempre y cuando la transmisión de mensajes afecte cualquier otra dimensión no comunicativa, será necesario distinguir quiénes son los ejecutantes de esa transmisión, y qué dimensiones o aspectos condicionan su actividad; igualmente, convendrá distinguir cuáles son los medios o recursos disponibles para que su transmisión sea efectuada y qué otros aspectos no comunicativos la condicionan; será necesario también tomar en consideración, finalmente, qué reglas se imponen en el propio juego de la transmisión de mensajes y qué reglas no comunicativas la condicionan o cambian por el juego de la comunicación.

Nuestra propuesta es distinguir que hay aspectos o dimensiones que condicionan, en primer lugar, el juego de los Actores de la comunicación: o son emisores o son receptores; estos aspectos proceden de la naturaleza de la transmisión de mensajes, pero otros aspectos proceden de la naturaleza del capital cognitivo que tienen disponible como Sujetos de interacción humana, o del rol social en virtud del cual actúan como Agentes cuando se comunican.

En segundo lugar, conviene distinguir que hay aspectos o dimensiones que atañen a los medios disponibles para producir, transmitir o recibir señales en la transmisión de mensajes, y que algunas de estas dimensiones proceden directamente del sistema físico elegido para la transmisión; pero también hay otras dimensiones en virtud de las cuales los medios disponibles resultan ser herramientas o útiles biológicos o tecnológicos de acomodación frente al entorno, así como dimensiones por las cuales los medios disponibles se convierten en medios de producción de bienes o servicios comunicativos (con un valor social de uso y de cambio).

En tercer lugar, debe considerarse que hay dimensiones o aspectos que atañen a la naturaleza de los mensajes, los cuales son expresiones desde el punto de vista de la comunicación, pero que desde la perspectiva del capital cognitivo invertido en el comportamiento interactivo resultan ser objetos de experiencia sometidos a fines humanos de la interacción frente al entorno, y productos (bienes o servicios) de la interacción social por la que se intercambian. 
Finalmente, en cuarto lugar, hay que considerar dimensiones referidas al orden impuesto a los ejecutantes en el ejercicio de cualquier interacción en que, usando unos recursos disponibles, se intercambia algo de forma no aleatoria; este orden, desde el punto de vista de la comunicación, atañe a la complejidad (información) de la transmisión de mensajes, reducida por la redundancia de pautas y códigos (lenguajes); pero este orden, desde el punto de vista biocognitivo, también atañe a la disponibilidad de categorías conceptuales y de lógicas operativas del comportamiento inteligente (capital cognitivo); y desde el punto de vista de la interacción social, existe un orden que afecta la interacción comunicativa en virtud de las normas y valores prescritos, que comprometen socialmente los papeles que se van a interpretar en la interacción (véase el cuadro 4).

\section{Cuadro 4}

Constantes de interacción y variables de sus dimensiones comunicativas, ecológicas y sociales

\begin{tabular}{|c|c|c|c|}
\hline $\begin{array}{l}\text { Campo de estudio: } \\
\text { Situaciones de } \\
\text { interacción }\end{array}$ & $\begin{array}{l}\text { Transmisión o intercambio } \\
\text { de mensajes } \\
\text { Sistema de comunicación [SC] }\end{array}$ & $\begin{array}{l}\text { Intercambio de } \\
\text { estímulos/datos } \\
\text { Sistema ecológico- } \\
\text { cognitivo [SE] }\end{array}$ & $\begin{array}{l}\text { Intercambio de } \\
\text { prestaciones: Sistema } \\
\text { de relación social [SS] }\end{array}$ \\
\hline Ejecutantes & $\begin{array}{l}\text { Actores } \\
\text { Emisores } \\
\text { Receptores }\end{array}$ & $\begin{array}{l}\text { Sujetos } \\
\text { Ego } \\
\text { Álter }\end{array}$ & $\begin{array}{l}\text { Agentes } \\
\text { Productores } \\
\text { Distribuidores } \\
\text { Consumidores }\end{array}$ \\
\hline Herramientas & $\begin{array}{l}\text { Instrumentos } \\
\text { Productores de señales } \\
\text { Distribuidores de señales } \\
\text { Receptores de señales }\end{array}$ & $\begin{array}{l}\text { Útiles } \\
\text { Asimilación } \\
\text { Acomodación }\end{array}$ & $\begin{array}{l}\text { Medios } \\
\text { Capital } \\
\text { Trabajo }\end{array}$ \\
\hline Producciones & $\begin{array}{l}\text { Expresiones (mensajes) } \\
\quad \text { Materias expresivas } \\
\text { Configuraciones expresivas }\end{array}$ & $\begin{array}{l}\text { Objetos } \\
\text { Perceptibles } \\
\text { Abstractos }\end{array}$ & $\begin{array}{l}\text { Productos } \\
\text { Mercancías } \\
\text { Bienes } \\
\text { Servicios }\end{array}$ \\
\hline Orden & $\begin{array}{l}\text { Lenguajes (o códigos) } \\
\text { Patrones expresivos } \\
\text { Códigos de significación }\end{array}$ & $\begin{array}{l}\text { Epistemes } \\
\text { Lógicas } \\
\text { Categorías }\end{array}$ & $\begin{array}{l}\text { Sanciones } \\
\text { Roles/estatus } \\
\text { Valores/normas }\end{array}$ \\
\hline
\end{tabular}


Todas estas dimensiones citadas atañen simultánea o sucesivamente a los ejecutantes de cualquier interacción en que la comunicación se hace presente, los recursos materiales o herramientas que la hacen posible, las entidades materiales o producciones que por la interacción se intercambian, y a las reglas de orden por las que la interacción se reproduce y no se desorganiza. Así, ejecutantes, herramientas, producciones y orden se consideran las constantes en cualquier campo espaciotemporal o situación de interacción a la que remiten tanto la transmisión de mensajes en la comunicación humana como el capital cognitivo que regula el comportamiento entre sujetos frente al entorno, como en las relaciones sociales.

La propuesta es tomar en consideración estas constantes y plantear los problemas que se derivan de considerarlas desde las dimensiones comunicativas, cognitivas y sociales, que las modifican cuando se examinan los procesos de cambio. Pero una representación esquemática tan detallada de variables o dimensiones susceptibles de modificar el juego de las constantes del campo de una interacción donde se hace presente la comunicación, exige el pormenorizado análisis de prácticas humanas encaminado a identificar cómo cambian aquellas variables y relaciones que, en cada situación de interacción, puedan atribuirse a la intervención de unos y otros elementos en cada sistema, y de uno $\mathrm{u}$ otro de los sistemas representados, respectivamente; de esta manera se podrán verificar las afectaciones entre los sistemas, y los órdenes de prelación (o antelación) en virtud de los cuales existen acuerdos culturalmente establecidos o implícitos por los que uno de los sistemas domina sobre los otros dos. Para comprender esto es necesario reparar en los juegos o "tableros" donde la relación entre ejecutantes, herramientas, producciones y regulaciones $\mathrm{u}$ orden contribuyen a hacer posible que se reproduzcan las condiciones de la interacción comunicativa, del comportamiento entre sujetos, y de la interacción social, conforme al orden histórico que fijan las praxis, sometiendo a la reproducción de uno de estos sistemas los otros dos.

\section{Lo que suceda en el "tablero" de la comunicación afecta a otros juegos en la sociedad y en el individuo, y viceversa}

Lo que suceda en el tablero de la comunicación afecta otros juegos en la sociedad y en el individuo, y viceversa. Imaginemos al telespectador con su mando a distancia, que al pasar por un determinado canal de televisión elige una opción y accede a una pantalla en la que puede leerse y escucharse de forma perpetua y monótona el siguiente mensaje: "Si quiere ser feliz no cambie de canal y siga prestando para siempre su atención a este mensaje". La historia de ese organis- 
mo vivo que es el telespectador (sus conocimientos y sus recuerdos, sus creencias y aspiraciones, o dicho en resumen, su capital cognitivo), así como la historia de sus relaciones y futuras actividades sociales, tanto como la previsión de sus prácticas comunicativas futuras, se encuentran en este momento en juego: es fácil imaginar que este telespectador decidirá no hacerle caso a aquel mensaje.

Esta situación constituye, en esencia, un estado determinado, temporalmente ubicado en un dominio de existencia en el que este telespectador (receptor de comunicación) de hecho no puede prescindir de su condición de sujeto cognitivo que controla su propia conducta en función de habilidades adquiridas a lo largo de su vida, ni de su condición de consumidor o usuario de bienes y servicios sociales comercializados por alguna cadena de televisión. Pues bien, este estado concreto en su dominio de existencia podría también considerarse, en consecuencia, un "hiperjuego" (un juego de juegos) en el que un mismo tablero y unas mismas fichas sirven para jugar varios juegos diferentes a la vez.

Obsérvese que cuando un telespectador realiza una selección en el mando a distancia de su televisor se están activando simultáneamente tres "juegos" o "sistemas" diferentes: el que nos presenta al telespectador como actor receptor de un determinado flujo de mensajes audiovisuales, cuyo contenido o significado interpreta según pautas y códigos compartidos con el emisor audiovisual (sistema de comunicación); el que nos presenta al telespectador como un sujeto (ego) que busca mediante esta actividad (mirar una pantalla jugando a cambiar el flujo de estímulos visuales con el telemando) un determinado ejercicio perceptivo por el que emplea su ocio usando lógicas y categorías según la oferta de entretenimiento que le ofrece su entorno (sistema ecológico-adaptativo); y el que nos presenta al telespectador como un agente consumidor, que disponiendo de medios adecuados elige una opción de la oferta de servicios que las cadenas de televisión, como productores, le ofertan al amparo de contratos y legislaciones vigentes (sistema económico-social).

De esta manera, los movimientos de ficha registrados en uno de los juegos (el sistema de comunicación mediante sonido e imagen en movimiento de la televisión, por ejemplo) solo pueden llegar a evaluarse, explicarse y comprenderse si se considera que las nuevas posiciones obtenidas sobre ese tablero condicionan a su vez el desarrollo de otros juegos simultáneos; verbigracia: el juego de la oferta y la demanda de las relaciones del sistema social en cuanto a producción y consumo de programas de televisión, y el juego de los hábitos de conducta y de los conocimientos, etcétera, de un adulto, en contraposición a los de un niño, conforme a un estado de su sis- 
tema adaptativo ecológico; esos cambios, que la práctica de la comunicación produce en el tablero al modificar las relaciones sociales y ecoadaptativas, condicionarán a su vez los siguientes movimientos de ficha en el propio juego de la comunicación.

Por esta razón es pensable, pero poco posible, que aquel telespectador de nuestro ejemplo quedase atrapado por el monótono mensaje que le invitaba a quedarse quieto y esperar a que llegase su felicidad prometida. Ni el territorio de las relaciones sociales ni el capital cognitivo disponible cuando se "mueven fichas" en el tablero de la comunicación permiten, en este caso, confiar en el éxito comunicativo del mensaje en cuestión. Lo que sucede, por el contrario, es que la reproducción de situaciones comunicativas se ajusta a prácticas sociales y cognitivas que la hacen posible; pero también que dichas prácticas sociales y cognitivas se reproducen, a su vez, por medio de las situaciones comunicativas que les resulten más pertinentes.

\section{Las partidas jugadas (cambios) y} su representación como "fichas", "tableros" y "reglas de juego" en un modelo de mediaciones entre la comunicación, la sociedad y el conocimiento

La concepción de procesos de comunicación, procesos de interacción social y procesos de comportamiento adaptativo al entorno, que recíproca- mente y de forma secuencial se afectan entre sí, exige suponer que tales procesos pertenecen a un campo que comprende sistemas de interacción formal y materialmente distintos, pues estos sistemas no se desorganizan internamente cuando uno sufre afectaciones de los otros; e incluso estos sistemas, por consiguiente, no son cerrados, sino abiertos unos a las influencias o determinaciones de los otros. Sirviéndonos de la misma metáfora ya empleada, las partidas jugadas (cambios) en un sistema producen cambios en los otros sistemas, y viceversa. La concepción de los sistemas de comunicación [SC], de los sistemas sociales [SS] y de los sistemas ecológico-adaptativos [SE] como sistemas abiertos entre sí nos permite describir la transformación histórica de cada uno de esos tres sistemas en términos de una mediación "íntersistémica"; es decir, concibiendo la transformación interna de un determinado sistema como el producto histórico de la influencia externa que ejercen sobre él los sistemas restantes, y viceversa.

De esta manera, los cambios en los [SC] se describirán normalmente identificando, en primer lugar, al menos dos estados del sistema de comunicación (correspondientes a dos momentos históricos diferentes), para una vez comparados y señaladas sus transformaciones examinar el valor que puede tener el análisis de la influencia ejercida en o por los [SS] y la influencia ejercida en o por los [SE] 
como factores explicativos del cambio experimentado por los [SC]. Si consideramos las estructuras y condiciones del conocimiento humano como componentes del sistema ecológico-adaptativo (sistema que regula, por definición, las relaciones entre el organismo humano y su entorno), será fácil comprender que el modelo propuesto (Piñuel y Lozano 2006, cap. 9) o Modelo de la Mediación Dialéctica de la Comunicación Social (en adelante MDCS) contiene implícitamente una cierta teoría acerca del cambio histórico de dichas estructuras y algoritmos. Desde esta teoría implícita, el cambio histórico de los [SE] podría igualmente conocerse (describirse, explicarse o predecirse) examinando el papel que juegan los [SC] y los SS en su transformación interna, y viceversa: examinando a su vez el papel que juegan los propios SE en la transformación de los otros dos sistemas.

Siguiendo con la metáfora propuesta anteriormente, las "fichas", los "tableros" y las "reglas de juego" construyen un campo o "hiperjuego" asimilable a un hipersistema que cambia por las partidas (movimientos de fichas) que se juegan en tres tableros: el de las relaciones sociales entre los interlocutores [SS], el de sus condiciones psicobiológicas como sujetos [SE] y el de sus intercambios de mensajes [SC]. Pues bien, a modo de ilustración, la propuesta es acotar ese hipersistema a un examen de caso: verbigracia una conversación. Es sabido que la transmisión del capital cognitivo de generación en generación y la construcción de las representaciones colectivas que en los grupos humanos sostiene la reproducción de rutinas y prescripciones para la reproducción del orden en una comunidad ocurren de manera fundamental mediante procesos comunicativos cara a cara del tipo de las conversaciones, hasta el punto de que, como indicara Ibáñez (1990: 189), la conversación pueda entenderse como la unidad mínima de la interacción social. De hecho, es difícilmente imaginable que sin conversaciones cara a cara pueda sostenerse la vigencia de los discursos escritos y cualesquiera otros tecnológicamente mediados, pues sería imposible aprender a utilizarlos $\mathrm{y}$ reproducirlos.

Pues bien, en los procesos comunicativos (por ejemplo, una conversación), el uso de los mensajes no se cierra en la transmisión de señales acústicas y visuales, sino que se abre a la relación que los interlocutores mantienen entre sí por sus diferentes posiciones sociales y psicológicas; a la diferente adecuación de sus órganos vitales respecto al intercambio de estímulos y reacciones producidas por los mensajes intercambiados; y al capital cognitivo con el que los interlocutores procesan la referencia o significación de los mensajes, los cuales aportan solo una parte de los datos que se pueden procesar en una representación; y, obviamente, cada cual, 
emisor y receptor, elabora su propia representación. Por ejemplo, en una conversación entre un mexicano y un español decir que "tengo un hijo muy salado" representa para el mexicano "tengo un hijo con mala suerte" y para el español "tengo un hijo muy simpático".

Concretamente, los órdenes del intercambio de expresiones, de la referencia cognitiva y de la interacción social se estructuran en los procesos comunicativos humanos:

- Asimilando condicionamientos sociales y ecológicos en las relaciones entre usuarios de los mensajes; por ejemplo, en una conversación entre un padre y su hijo, los condicionamientos sociales proceden de la institución familiar y los condicionamientos ecológico-cognitivos proceden de las diferencias de sus experiencias vitales.

- Integrando rutinas biológicas y culturales en la codificación y decodificación de mensajes; por ejemplo, si el padre es bastante mayor y el hijo muy menor, sus diferentes biorritmos provocan conflictos que culturalmente se han reflejado en muchas sociedades, estableciendo pautas protocolarias de respeto entre ellos, de convivencia y de familiaridad.

- Poniendo en juego nociones y operaciones bastante contingentes en la elaboración de datos o referencias; por ejemplo, entre un padre bastante mayor y un hijo muy menor es presumible el diferente juego de nociones y operaciones referidas al sexo como tema de conversación.

Así, la estructuración de aquellos condicionamientos, esas rutinas y estas nociones y operaciones será absolutamente necesaria, pues si esta estructuración faltase, la comunicación humana sería difícilmente integrable en su interacción; en efecto, no podría darse comunicación sin recurrir incesantemente a la meta comunicación, y esta última exigiría nuevas metacomunicaciones, y así sucesivamente, ya que el objeto de toda metacomunicación, es decir, toda comunicación a propósito de la comunicación en curso, está dirigido a reducir la ambigüedad de los órdenes del intercambio expresivo, de la referencia cognitiva o de la interacción social, en los procesos comunicativos concretos. Por eso es necesario que en la sociedad, el grupo o la situación existan sistemas de regulaciones ya institucionalizados, o de formato estable, tanto para el intercambio expresivo, la interacción social como para la referencia cognitiva. Pero un análisis pormenorizado de esos sistemas de regulaciones ya institucionalizados excede los límites de este artículo. Concluyo esta exposición ofreciendo, primero, la representación estructural de las relaciones entre los sistemas y sus componentes, dentro de un entorno o campo (que se propone denominar Sistema Umwelt) y que se corresponde con las 
prácticas culturales a la escala que se establezca para el análisis (ya sea, como se ha expuesto antes, a pequeña escala, por ejemplo una comunidad, una empresa o un colectivo religioso; a gran escala, verbigracia una época histórica o una cultura); y segundo, la representación diacrónica de las relaciones entre los sistemas, considerando la evolución histórica. El cuadro 5 representa el modelo estructural, sin especificar la escala del Umwelt, y el gráfico 5 ofrece la representación diacrónica de las relaciones entre los sistemas, considerando la evolución histórica, que luego se ilustra con un ejemplo (gráfico 6).

Según el cuadro 5, donde se citan todos y cada uno de los componentes de cada sistema ya conocidos, se representan conceptualmente, en primer lugar, las relaciones dos a dos entre los sistemas, asignándoles un término procedente de la tradición en ciencias humanas. Así, el ajuste entre la interacción social [SS] y el intercambio comunicativo de mensajes [SC] da lugar a lo que se propone denominar preceptiva, pues todo precepto es un ordenamiento normativo social que se expresa mediante enunciados comunicativos; el ajuste entre el intercambio comunicativo [SC] y la perspectiva cognitiva de apropiación del entorno [SE] da lugar a la inteligibilidad de los discursos; por último, el ajuste entre la interacción social y la perspectiva cognitiva de apropiación del entorno da lugar a lo que hemos denominado Ergonomía, noción que, como se sabe, compromete a facilitar la adecuación entre los procesos de trabajo (propios del sistema social de producción) y los condicionamientos psicobiológicos derivados de las capacidades y destrezas de los sujetos humanos.

En el gráfico 5 se muestra la perspectiva diacrónica, considerando diferentes estados del hipersistema Umwelt (y de cada uno de los sistemas que lo componen) y examinando su evolución a lo largo de la historia. Para representar gráficamente la evolución histórica conjunta de los sistemas de comunicación [SC], social [SS] y ecológico [SE], se emplea el recurso figurativo de una espiral. La espiral, como se sabe, posee la paradójica propiedad de compatibilizar reproducción y cambio, ya que a pesar del carácter cíclico de la expansión espacial de la curva, esta nunca vuelve a pasar por un mismo punto.

La representación del modelo de la MDCS haciendo uso de espirales debe suponerse proyectada en un espacio tridimensional. El gráfico 5 muestra un tramo determinado de la historia de Umwelt, es decir, del orden de las mediaciones entre sistemas (intersistémicas), que en realidad se traduciría en una espiral irregular (de evolución no regulada por una razón matemática constante) y que si en este gráfico se presenta como "regular" es con el objeto de ilustrar la idea de que el cambio de cada sistema se encuentra mediado por los sistemas restantes $\mathrm{y}$, a su vez, opera como mediador del cambio histórico de dichos sistemas. 


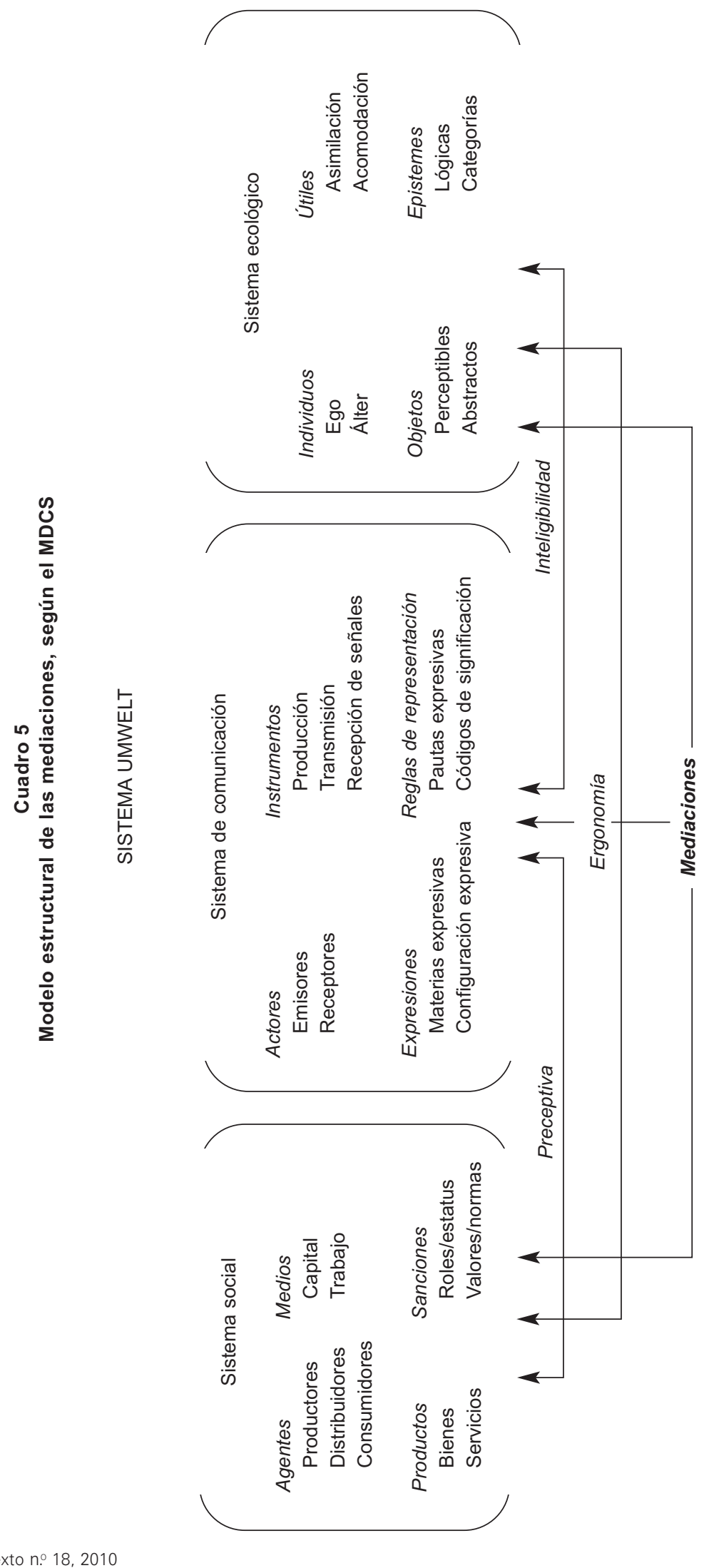

100 Contratexto n. 18,2010 


\section{Gráfico 5}

Esquema de la evolución diacrónica de las mediaciones

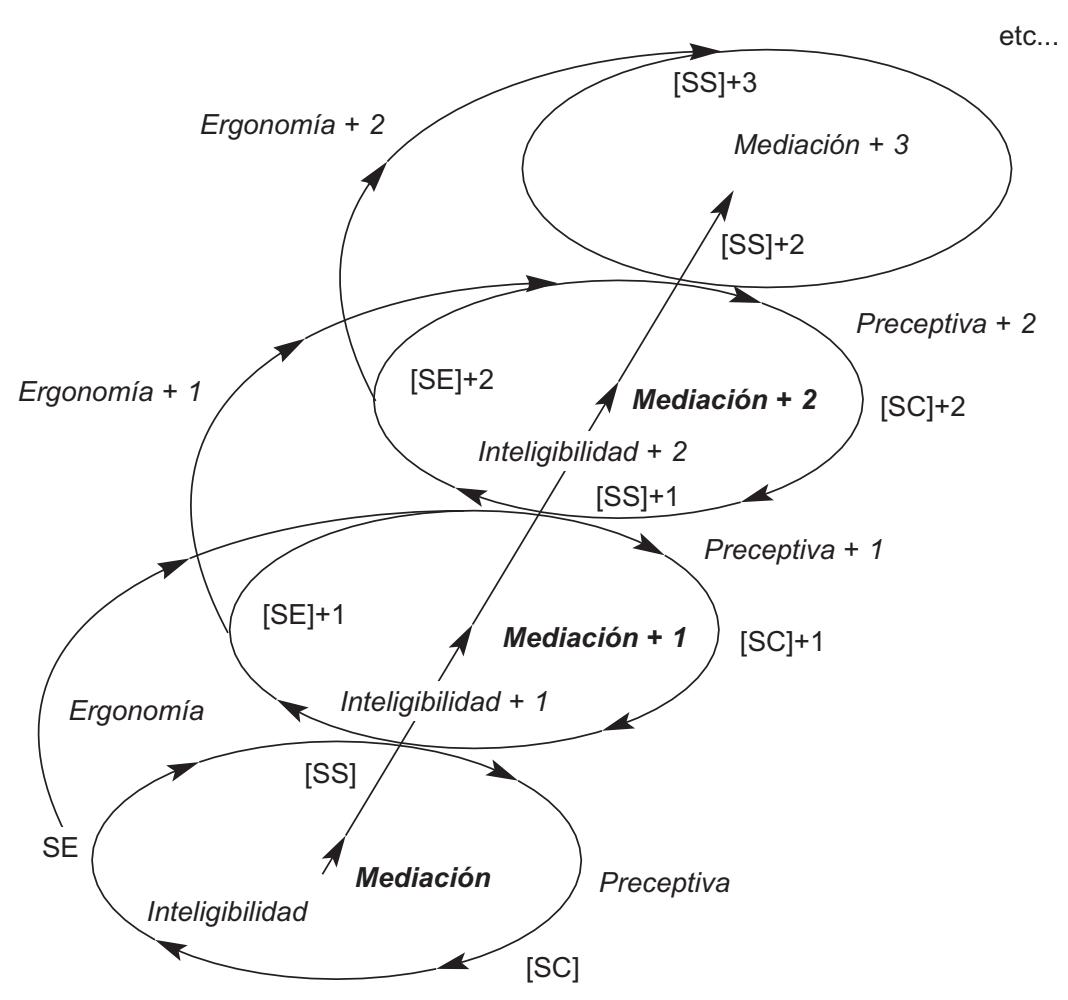

Para ilustrar con un ejemplo cómo los cambios intersistémicos se reproducen secuencialmente en el tiempo, podemos examinar ciertas rutinas en los medios de comunicación de masas, pues existen socioesquemas que permiten descubrirlos. En el gráfico 6 se comparan sendos formatos de televisión fácilmente identificables: Publicidad y Teleconcursos.
Los socioesquemas de género, que son activados espontáneamente en la mente de los telespectadores cuando hacen zapping con el telemando, comprenden rasgos en función de los cuales se identifica en pocos segundos la naturaleza de los programas que aparecen en pantalla, y se comparten creencias por las que puede hablarse de "dominios de realidad" diferentes, 
tal como se muestra en el gráfico 6, y que el lector puede entender a estas alturas del discurso teórico propuesto, ya que se ha resaltado en color y con flechas desde el texto con las formulaciones, las trayectorias de la espiral que se corresponden con cada formato.

De acuerdo con estos postulados, el MDCS permite con carácter general tomar en consideración todas las mediaciones posibles, que serían estas:
- Dado un estado propiciado por el Sistema Social [SS]+1, por ejemplo, se recurre a la comunicación [SC]+1 para promover un cambio en el sistema de adaptación al entorno por parte de los sujetos, o sistema ecológico [SE] +1 , de manera que esto último redunde en beneficio del Sistema Social, que adquiere así un nuevo estado [SS]+2 (así ocurre en la práctica publicitaria, véase gráfico 2); o bien, en sentido inverso de

Gráfico 6

Formulación gráfica del modelo diacrónico de la MDCS: Ejemplos

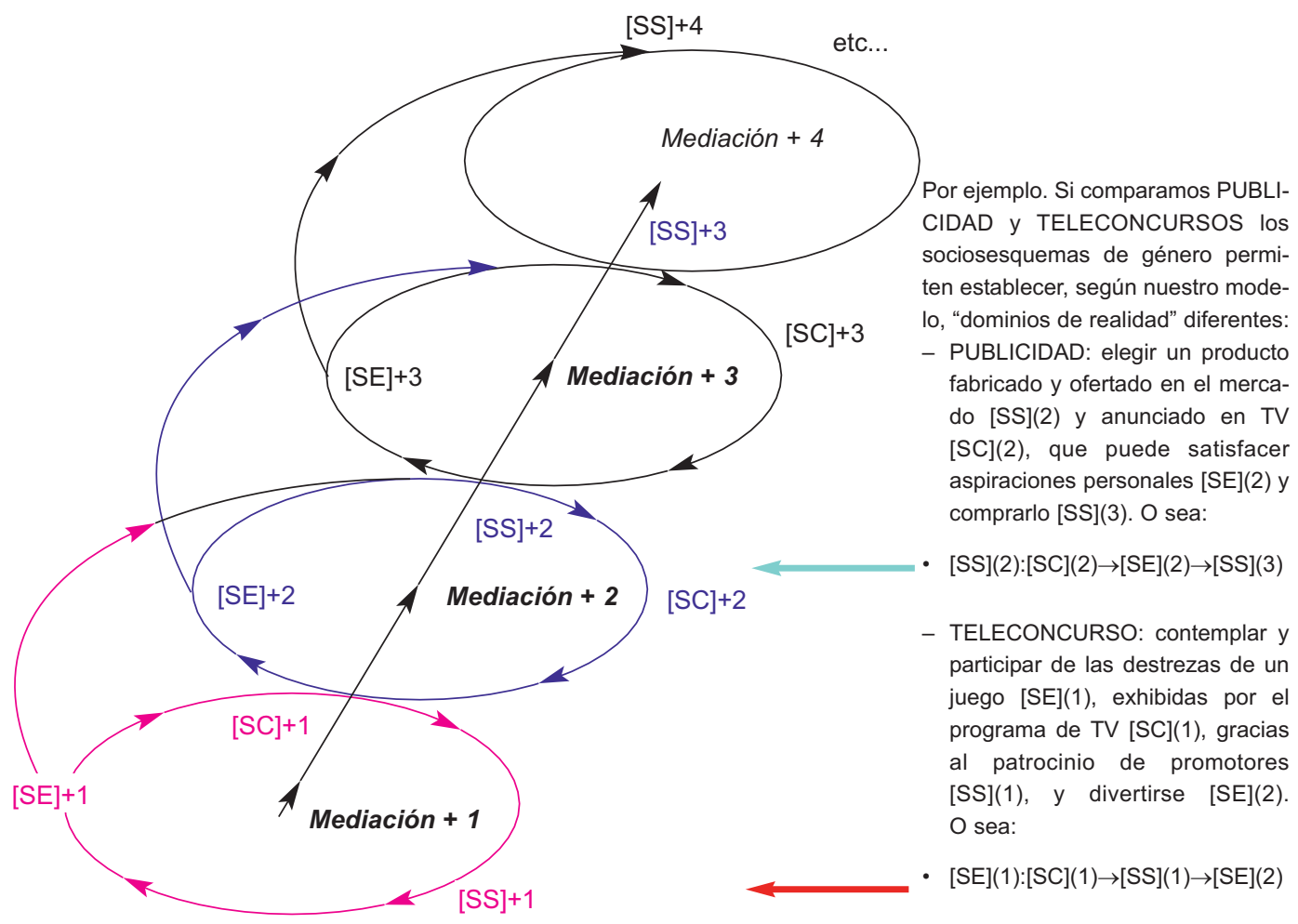


la espiral, se recurre al Sistema Ecológico [SE]+1 para promover un cambio en el Sistema de Comunicación [SC]+1, que redunde en beneficio del Sistema Social, el cual adquiere un nuevo estado [SS]+2 (así ocurre en la práctica de la didáctica en la escuela, cuyo servicio educativo orientado a la formación de los niños, como sujetos, promueve el aprendizaje de la comunicación, la que habrá de servir a la reproducción del orden social). En ambos casos, el Sistema de Comunicación resulta mediador del cambio en el Sistema Social. Pero en el primer caso, la Mediación Social de la Comunicación se ejerce por la intervención de la comunicación sobre el sistema ecológico, y en el otro por la intervención del sistema ecológico sobre el sistema de comunicación (mediaciones cognitivas de la comunicación que se sostienen por el criterio de inteligibilidad).

- Dado un estado propiciado por el Sistema Ecológico, por ejemplo [SE]+2, o de adaptación al entorno por parte de los sujetos, se recurre a la comunicación [SC]+2 para promover un cambio en el sistema social [SS]+2, de manera que esto último redunde en beneficio del Sistema Ecológico, que adquiere así un nuevo estado [SE]+3; un ejemplo de ello se da cuando los sujetos en estado de enamoramiento recurren al ritual comunicativo de la boda, con el objeto de que gracias a él se legitime socialmente una unión amorosa que puede adquirir nuevo rumbo; o bien, en sentido inverso de la espiral, se recurre al sistema social [SS]+2 para promover un cambio en la comunicación $[\mathrm{SC}]+2$, de manera también que esto último redunde en beneficio del Sistema Ecológico, que adquiere así un nuevo estado [SE]+3; un ejemplo de esto se da cuando se acude a comprar servicios de compañías operadoras en telecomunicaciones, con el objeto de entablar fácilmente intercambios comunicativos a distancia que nos sirvan para mantener contactos frecuentes con los seres queridos. En estos casos puede hablarse de Mediación Ecológica del Sistema de Comunicación, ejercida ya sea por la intervención de la comunicación sobre el sistema social, o por la intervención del sistema social sobre el sistema de comunicación (mediaciones estructurales de la comunicación que se sostienen por el recurso a la Preceptiva), para promover un cambio en las relaciones entre sujetos y entorno [SE].

- Dado un estado propiciado por el Sistema de Comunicación [SC]+3, se recurre al Sistema Social [SS]+3 para promover un cambio en el sistema de adaptación al entorno por parte de los sujetos, o sistema ecológico $[\mathrm{SE}]+3$, de manera que 
esto último redunde en beneficio del Sistema de Comunicación, que adquiere así un nuevo estado [SC]+4; un ejemplo de esto se da cuando usamos una conexión a través de operadoras de telecomunicaciones para contactar personalmente con alguien al objeto de confirmar, por esta vía, si está disponible para proseguir una conversación iniciada con anterioridad y por otros procedimientos. $\mathrm{O}$ bien, en sentido inverso de la espiral, se recurre al sistema ecológico [SE]+3 para promover un cambio en el sistema social [SS]+3, de manera también que esto último redunde en beneficio del Sistema de Comunicación, que adquiere así un nuevo estado $[\mathrm{SC}]+4$. Un ejemplo lo encontramos en muchas prácticas vigentes de los rituales comunicativos de la seducción, especialmente cuando, verbigracia, el varón se ampara en su condición profesional de cierto prestigio para vencer las resistencias de la mujer, limando así asperezas en la relación... En estos casos, finalmente, se trata de una Mediación Metacomunicativa de la Comunicación, la cual requiere de mediaciones ergonómicas que comprometen los ajustes de los recursos sociales y de capital cognitivo disponibles para hacer que la propia comunicación se reproduzca sirviéndose de ellos.

Naturalmente, el MDCS permite emprender un programa de investiga- ción encaminado al análisis de las prácticas vigentes en nuestra cultura (pero también podría ser aplicado al estudio de otras culturas) capaz de progresar en el análisis de las mediaciones.

Cómo se juega: La lógica de la investigación (el estudio de los cambios) y la lógica de la competición (el diseño de las estrategias comunicativas que generan cambios)

Una vez definidas y comentadas las "fichas", "tableros" y "reglas" que nos pueden permitir acercarnos al análisis de las praxis históricas de la interacción humana cuando la comunicación se hace presente, el modelo de la MDCS puede brindarnos muchas oportunidades de "juego". Así, el modelo de la MDCS sirve en primer lugar para "descubrir el juego" de los participantes que, por supuesto, saben ya jugar, pero que sin embargo lo hacen (lo hacemos todos) de manera inconsciente, sin advertir lo que está detrás del juego en nuestras rutinas diarias.

Con la comunicación nos ocurre lo que al conductor de un automóvil, que sabe ponerlo en marcha y servirse de él con destreza y evitando muchos obstáculos, pero que sin embargo desconoce el diseño interno del vehículo (el motor y el funcionamiento de todos los resortes de los que se sirve para conducir), desconoce igualmente 
el diseño urbanístico y arquitectónico de las vías de circulación y, por supuesto, desconoce las maniobras que otros conductores están realizando a la vez sobre la vía por la que él circula. Inversamente, no es seguro que si conociese (o conociésemos) plenamente el automóvil, las vías de circulación y todo aquello que otros hacen andando y circulando por las vías, esto nos permitiera conducir bien; una cosa es la práctica que se domina cuando se adquieren las rutinas que exige la conducción, y otra es la "teoría" o representación disponible sobre las condiciones del tráfico, dependiendo de cuál sea el capital cognitivo social y comunicativamente acumulado que ha sido necesario para construir vehículos, vías de circulación y leyes vigentes para ordenar el tráfico. $Y$, naturalmente, cuanto más y mejor revisemos estas prácticas rutinarias y aquellas "teorías" o representaciones colectivas que han hecho posible la fabricación de vehículos, carreteras y "pautas" de buena conducción, más y mejor podremos conducir, pues los vehículos y vías de tráfico se adecuarán mejor al cambio y facilidad de las rutinas, y las leyes de circulación también se ajustarán mejor a la seguridad del transporte y la circulación.

Asimismo, sabemos poner en marcha la comunicación y servirnos de ella a veces con destreza y evitando muchos malentendidos, pero sin embargo desconocemos el diseño interno de los medios disponibles (desde los de nuestro propio cuerpo hasta los instrumentos artificiales o electrónicos de los que nos servimos para comunicar); desconocemos igualmente el diseño industrial y social de los medios de comunicación; y, por supuesto, desconocemos las maniobras comunicativas que otros comunicadores están realizando a la vez sobre el terreno cultural en que nos apoyamos para hacernos entender, y a la inversa, no es seguro que si conociésemos plenamente nuestro cuerpo y todas las herramientas de que nos servimos para comunicar, así como las vías de comunicación y todo aquello que otros hacen para comunicarse a través de ellas, nos permitiera comunicar bien; una cosa es la práctica que se domina cuando se adquieren las rutinas que exige la comunicación, y otra es la "teoría" o representación disponible sobre las condiciones de la comunicación, dependiendo del capital cognitivo social y comunicativamente acumulado que ha sido necesario para construir instrumentos de comunicación, fabricar textos y discursos, así como vías de comunicación y leyes vigentes para ordenar el derecho a la comunicación y la información. $Y$, naturalmente, cuanto más y mejor revisemos estas prácticas rutinarias y aquellas "teorías" o representaciones colectivas que han hecho posible la fabricación de textos y discursos, medios de comunicación y "normas" de buena comunicación, 
más y mejor podremos comunicar, pues los mensajes y vías de transmisión y comunicación se adecuarán al cambio y facilidad de las rutinas, y las leyes sobre la comunicación también se ajustarán a la fiabilidad de las redes de la circulación de mensajes y contenidos.

En segundo lugar, el modelo de la MDCS sirve para "cambiar el juego" de la comunicación, pues sabiendo "cómo se juega" y, sobre todo, "lo que uno se juega en ello", pueden plantearse innovaciones encaminadas a mejorar las prácticas comunicativas, sabiendo cómo hacerlo. Dicho de otra manera, el modelo de la MDCS, por una parte, diseña más certeramente una lógica de la investigación científica para, una vez acotado y definido un campo o dominio de existencia (prácticas comunicativas de un grupo humano, una comunidad, etcétera), estudiar sus cambios en el tiempo. El modelo de la MDCS permite también, finalmente, aprovechar más certeramente la lógica de la competición, es decir, la lógica del juego por medio del cual la comunicación genera cambios en la sociedad y el conocimiento, y a la inversa, de modo que se puedan diseñar las estrategias comunicativas generadoras de aquellos cambios que merece la pena intentar.

\section{Bibliografía}

BACHELARD, G. (1973). Epistemología. Barcelona: Anagrama.

_ (1972). La formación del espíritu científico. Buenos Aires: Siglo XXI.

BATESON, G. et al. (1984). La nueva comunicación. Barcelona: Kairós.

— (1980) Espíritu y naturaleza. Buenos Aires, Amorrortu.

BEAVIN, J. H. y D. D. Jackson (1983). Teoría de la comunicación humana. Barcelona: Herder.

BertalanfFy, L. von (1976). Teoría general de los sistemas. Fundamentos, desarrollo, aplicaciones. México: Fondo de Cultura Económica.

DEACON, T. W. (1997). The symbolic species: the co-evolution of language of the brain. Nueva York: W. W. Norton \& Co.

GARfinKel, H. (1967). Studies in Ethnomethodology. Nueva York: Prentice-Hall.

IBÁÑEZ, J. (1986). Más allá de la sociología. El grupo de discusión: Crítica y técnica. Madrid: Siglo XXI.

(1990). "Nuevos avances de la investigación social". Suplemento 22. Barcelona: Anthropos. 
LEYDESDORFF, L. (2003). A sociological theory of communication. The selforganization of the knowledge-based society. Parkland, FL: Universal Publishers.

LLEDÓ, E. (1961). El silencio de la escritura. Madrid: Espasa.

LUHMANN, N. (1991). Sistemas sociales: Lineamientos para una teoría general. México: Universidad Iberoamericana.

MaturAnA, H. y F. Varela. (1996 [1984]). El árbol del conocimiento. Madrid: Debate.

__ (1995 [1973]). De máquinas y seres vivos. Santiago de Chile: Universitaria.

Moles, A. (1978). Sociodimánica de la cultura. Buenos Aires: Paidós.

Piaget, J. (1985). Psicología y epistemología. Barcelona: Planeta-Agostini.

Piñuel Raigada, J. L. y J. A. Gaitán Moya. (1995). Metodología general.
Conocimiento científico e investigación en la comunicación social. Madrid: Síntesis.

Piñuel, J. L. y C. Lozano. (2006). Ensayo general sobre la comunicación. Barcelona: Paidós.

RANKE, L. von (1954). Epochen. Darmstadt.

SHANNON, C. y M. WEAVER (1981 [1948]). Teoría matemática de la comunicación. Madrid: Forja.

Vigotsky, L. (1988). El desarrollo de los procesos psicológicos superiores. México: Crítica/Grijalbo.

WATZLAWICK, P. (1981). ¿Es real la realidad? Confusión, desinformación, comunicación. Barcelona: Herder.

Westfalen, M. H. y J. L. Piñuel (1993). La dirección de comunicación. Práctica profesional y diccionario técnico. Madrid: Ediciones del Prado. 